\title{
CAMBIO SOCIAL Y DESIGUALDADES EN LOS PAÍSES DEL MEDITERRÁNEO
}

\section{Jordi Caïs Fontanella}

Universidad de Barcelona

\section{RESUMEN}

El desarrollo de los países de la cuenca mediterránea es un fenómeno sociológico importante. En el presente artículo se analiza la evolución reciente de algunos factores que contribuyen a explicar la mejora de calidad de vida que se produce a lo largo de las dos últimas décadas del siglo XX en los países del sur y este de la cuenca mediterránea. Se considera que la calidad de vida es un factor vinculado a la cultura, al sistema de vida y al desarrollo que se mide en términos de bienestar y no en términos económicos. En el artículo se analiza la evolución atípica de los sectores económicos y el mercado laboral en los países africanos y asiáticos de la cuenca en comparación con los europeos. También se evalúa la creación y puesta en marcha de políticas públicas por parte de gobiernos africanos y asiáticos y se contrasta su eficacia con las políticas de los países mediterráneos europeos.

Los países del sur y este de la cuenca mediterránea (descontando a Israel y Chipre) suelen ser considerados países no industrializados. La aportación de su sector industrial al PIB es baja. Desde la década de los sesenta, la preocupación económica principal de los gobiernos de esos países africanos y asiáticos es crear un sector industrial importante. La mayor parte de los países fallan en ese intento. La economía se desarrolla pasando sobre todo del sector primario al terciario; se desagrariza para convertirse en un sistema económico cada vez más basado en el sector servicios. Este fenómeno no conlleva progresos económicos espectaculares, aunque sí deriva en mejoras de la calidad de vida de las personas. 
Es posible argumentar que la industrialización relativamente fallida y la terciarización de la economía en los países del sur y este de la cuenca mediterránea es una consecuencia directa de dos factores. Deriva de la estrategia económica que llevan a cabo la mayoría de esos países a partir de la década de los sesenta y de las políticas económicas que plantean los gobiernos para reajustar la economía. Un factor común es el papel que ejerce el Estado a la hora de estructurar la economía y organizar el desarrollo. La política económica en una buena parte de los países del sur y este del Mediterráneo proviene de una mezcla de ideas socialistas e islámicas que dan forma a los métodos utilizados para conducir el desarrollo económico y definen los objetivos. Se trata de evitar el control externo de la economía del país intentándola estructurar según principios ideológicos propios.

En Argelia y Libia se organiza la economía alrededor de una estructura basada en la industria vinculada al sector de los hidrocarburos, y que está centralizada en manos del Estado. La economía se desarrolla así alrededor de un sector público importante y controlador ${ }^{1}$. En la década de los sesenta, también Marruecos, Túnez, Egipto y Siria realizan inversiones masivas en proyectos del Estado. El punto de vista de cómo debe plantearse el desarrollo económico en el país no difiere del de Argelia o Libia. Posteriormente, esos países definen políticas económicas que no son ni capitalistas ni socialistas. Es un modelo mixto en el que los sectores público y privado deben estar delimitados a áreas específicas. En el desarrollo de los recursos naturales, la industria pesada y, sobre todo, en proyectos grandes — como, por ejemplo, los de irrigación- es el Estado quien ejerce el control. Mientras que en otros sectores de la industria, así como en el sector agrario y el de servicios, el actor es el sector privado. Sólo Turquía, Israel, Chipre y el Líbano discrepan de esta manera de plantear la economía y se desarrollan a partir de un modelo más liberal.

El desarrollo de la economía alrededor de un modelo basado en el control de la industria por parte del Estado tiene ciertos problemas. La economía de los países del sur y este de la cuenca no se desarrolla tanto ni tan rápidamente como se esperaba por esos mismos países. Pero ese relativo fracaso económico no implica que a lo largo de las últimas tres décadas las variables indicativas de bienestar social no se desarrollen. La mentalidad del Estado tiende a que esos países (del sur y este de la cuenca mediterránea) inviertan una parte importante del PIB en el sector público y se creen políticas sociales que potencian la sanidad y la educación de las personas. Por otro lado, el relativo fracaso de la industrialización obliga a que la economía de esos países se terciarice, es decir, que se desarrolla el sector servicios. La característica principal de las economías de los países mediterráneos africanos y asiáticos es que se terciarizan directamente desde el sector primario. El proceso de transformación de la economía no se produce a la manera tradicional, de la agricultura a la industria y de la

${ }^{1}$ La reorganización del sistema económico libanés llevada a cabo por el Coronel Gadafi se describe en el «Libro Verde» que se supone escrito por él mismo. 
industria a los servicios. Al fracasar en la mayoría de países el intento de industrialización rápida, se desarrolla al mismo tiempo un sector terciario importante. Puede resultar paradójico que el fracaso en el desarrollo de un modelo económico pueda repercutir directamente en un aumento de la calidad de vida de las personas, pero así parece que sucede en las últimas décadas del siglo XX.

\section{DESARROLLO ECONÓMICO VERSUS CAMBIO SOCIAL}

En la década de los sesenta y los setenta, la agricultura es uno de los factores más importantes en la economía de los países africanos y asiáticos de la cuenca mediterránea. Esa tendencia cambia durante los ochenta y principios de los noventa, cuando el sector primario pierde gran parte de su importancia ${ }^{2}$. Durante las dos últimas décadas del siglo XX se desarrollan los otros dos sectores económicos, pero principalmente el sector de servicios. Al fracasar en la mayoría de países africanos y asiáticos de la cuenca el intento de industrialización de las economías, éstas desarrollan directamente el sector terciario.

La producción agraria es difícil en el sur y este de la cuenca mediterránea. Las condiciones naturales no son favorables para la producción agrícola debido al clima árido o semiárido en casi todos los países. Hay escasez de terrenos irrigados, por lo que la agricultura se desarrolla principalmente en zonas costeras. El problema en esas zonas es el grado alto de variabilidad de las precipitaciones. No existe seguridad de lluvias en las diferentes estaciones. Las cosechas están sujetas a fluctuaciones considerables de un año a otro. A las condiciones naturales desfavorables hay que sumarle también los problemas derivados de la utilización de técnicas de producción primitivas, de unos patrones de propiedad de la tierra arcaicos y de sistemas de crédito rural poco desarrollados. El sistema de producción tradicional es el de subsistencia. Puesto que las condiciones son desfavorables para la producción agraria, los países del sur y este de la cuenca no llevan a cabo el paso de mecanizar la agricultura y producir a gran escala. En los últimos tres quinquenios se produce un éxodo de personas del campo a la ciudad. A pesar de la importancia de los planes nacionales para promocionar la agricultura de regadío y la ganadería industrializada, se abandona la agricultura y ganadería de subsistencia sin que se desarrollen sistemas eficientes de producción agraria a gran escala.

La producción agraria se incrementa ostensiblemente entre 1980 y 1993 en todos los países del bloque sur, excepto en Libia, donde disminuye, y en Israel, donde incrementa poco (véase la tabla 1$)^{3}$. En ningún caso el incremento de la producción es demasiado importante en valores absolutos si se consi-

2 En 1992, el valor añadido de las actividades vinculadas al sector primario en la mayoría de países del bloque sur es menos del 10 por 100 de PNB.

3 En Israel, igual que en los países de la Europa mediterránea, en 1980 la agricultura ya está especializada y técnicamente desarrollada; no necesita de cambios estructurales grandes que deriven en aumentos de producción importantes. 


\section{TABLA 1}

Producción agraria en 1993

(Número índice 1980=100)

\begin{tabular}{|c|c|c|c|c|}
\hline $\begin{array}{l}\text { Paises de la cuenca } \\
\text { mediterránea }\end{array}$ & $\begin{array}{l}\text { Todos los } \\
\text { productos }\end{array}$ & $\begin{array}{l}\text { Productos } \\
\text { alimenticios }\end{array}$ & Cereales & Carne \\
\hline \multicolumn{5}{|l|}{ Norte } \\
\hline Francia & 103 & 103 & 116 & 110 \\
\hline Italia & 103 & 103 & 109 & 112 \\
\hline 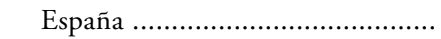 & 115 & 115 & 93 & 178 \\
\hline 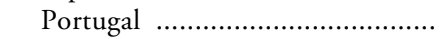 & 103 & 103 & 92 & 145 \\
\hline 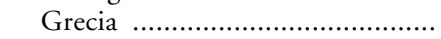 & 112 & 104 & 92 & 106 \\
\hline 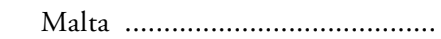 & 134 & 134 & 112 & 550 \\
\hline 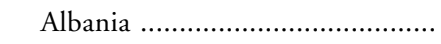 & 107 & 110 & 69 & 85 \\
\hline \multicolumn{5}{|l|}{ Sur } \\
\hline 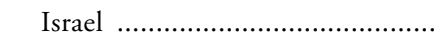 & 111 & 128 & 76 & 153 \\
\hline 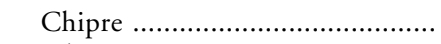 & 137 & 137 & 158 & 180 \\
\hline 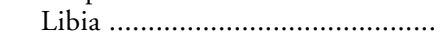 & 84 & 84 & 141 & 61 \\
\hline 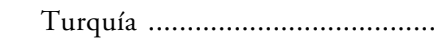 & 134 & 136 & 130 & 159 \\
\hline 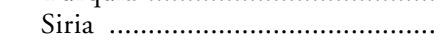 & 135 & 134 & 139 & 139 \\
\hline 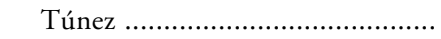 & 189 & 169 & 160 & 157 \\
\hline 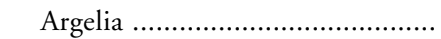 & 174 & 173 & 83 & 224 \\
\hline 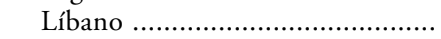 & 152 & 152 & 65 & 151 \\
\hline 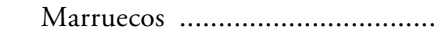 & 158 & 170 & 175 & 297 \\
\hline 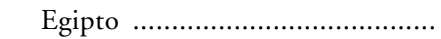 & 192 & 197 & 180 & 119 \\
\hline
\end{tabular}

FUENTES: United Nations, Statistical Yearbook 1985-86 (Nueva York: United Nations, 1988), pp. 358-360 y 482-493; United Nations, Statistical Yearbook 1993-94 (Nueva York: United Nations, 1995), pp. 299-313 y 392-417.

dera que se parte de productividades bajas y que, en la mayoría de países del área, las mejoras en las cosechas se ven limitadas por el crecimiento rápido de la población. Para poder desarrollar la explotación de los recursos agrarios a gran escala y extender los regadíos es necesario que los países del bloque sur de la cuenca aseguren una provisión de agua suficiente para las cosechas. Pero el proyecto de extender la producción agraria a partir de una utilización creciente de las reservas de agua para convertirse en países autosuficientes en producción de comida parece estar abocado al fracaso. En la década de los ochenta se desarrollan programas de regadío a gran escala en varios países ${ }^{4}$. La intención es

${ }^{4}$ Uno de los proyectos más importantes es el «Proyecto del gran río hecho por el hombre» (Proyecto GMR), en Libia. El proyecto, que está completamente financiado por los fondos propios del país, se inicia en 1994 e implica el desvío de las reservas de agua subterránea de los acuíferos de Sarir y Kufrah a través de una tubería hasta la zona costera. Marruecos también desarro- 
crear áreas nuevas de agricultura extensiva para cultivar cereales y crear zonas de pastos para el ganado.

Todos esos proyectos no son una solución al problema de la escasez de agua para llevar a cabo actividades agrarias y ganaderas. El coste es alto y los resultados no demasiado satisfactorios. Las reservas de agua susceptibles de ser utilizadas para regar a lo largo de un período de tiempo sostenido sin que se produzcan daños ecológicos son limitadas. Gran parte de esas reservas son de origen fósil y no pueden ser renovadas. La utilización intensiva de estos recursos para la producción agraria conllevaría una caída del nivel de agua y, a la larga, el abandono de los cultivos. Existe escasez de agricultores y ganaderos con conocimientos y capital suficiente para cultivar terrenos de regadío nuevos o utilizar los pastos.

La mayoría de los países africanos y asiáticos de la cuenca mediterránea no son autosuficientes. A pesar de ciertos incrementos de productividad en el sector agrícola y ganadero, no son capaces de cubrir su propia demanda de comida. Casi todos los países del sur y este de la cuenca deben importar cantidades significativas de cereales, carne y leche. Estas importaciones provienen principalmente de la Unión Europea y de Estados Unidos. La importación de cereales es la más importante en cuanto a cantidad. Los gobiernos de los países africanos y asiáticos del Mediterráneo, en sus proyectos de desarrollo, intentan paliar el problema de la escasez de cereales. Los proyectos de regadío en la región tienen el objetivo primario de catapultar la producción propia de cereales. Por el momento, aunque la mayoría de esos países aumentan la producción de cereales, aún están lejos de ser autosuficientes ${ }^{5}$.

Es complicado modernizar la economía de un país pasando directamente de un sector primario primitivo y de economía de subsistencia a uno dominado por la agricultura industrial consumidora de un mínimo de recursos para conseguir la máxima productividad. Los países del sur y este de la cuenca consiguen resultados parciales con sus políticas agrarias. Incrementan la producción agraria y ganadera a lo largo de la segunda mitad de la década de los ochenta y la primera de los noventa, y el aumento de producción es poco significativo pues para calcularlo se parte de producciones bajas. El aumento se debe más a un crecimiento de la demanda interna en esos países, derivada del incremento del nivel de vida de las personas, que a la implantación de procesos

lla un proyecto de regadío importante: el «Programa Sebou», en la región de Gharb, que cubre el área que va desde los alrededores de Fez y Mequines, en el Atlas Medio, hasta la costa atlántica, cerca de Kenitra y Rabat. El proyecto, iniciado en 1980, conlleva la construcción de trece presas y la creación de 200.000 hectáreas de regadío en un período de veinticinco años. Los planes de desarrollo de Argelia y Túnez también dan prioridad a la extensión de la agricultura de regadío, y reciben apoyo financiero de los fondos de ayuda al desarrollo, tanto bilaterales como multilaterales.

5 Libia es el ejemplo más claro: en 1992, este país importa casi el 90 por 100 de los cereales que necesita la población; por lo tanto, aunque los proyectos de desarrollo agrario fuesen exitosos, en el mejor de los casos sólo solucionarían parte de la escasez. Libia seguiría siendo dependiente de las importaciones foráneas. 
modernos de producción que mejoren la productividad agrícola. Tan sólo Marruecos y Túnez exportan algunos productos agrarios, pero son productos, como la aceituna, que demandan técnicas limitadas de producción modernas.

Ante la dificultad de modernizar los países del sur y este de la cuenca a partir de una mejora del sector primario, los gobiernos vuelcan la mayoría de recursos en el sector secundario. El desarrollo de la industria se realiza a partir de la producción energética, que es el producto clave de varios de los países del bloque sur. Aunque la exportación de petróleo se reduce a cinco de los diez países del sur (Libia, Argelia, Egipto, Túnez y Siria), globalmente es el producto de exportación más importante en el área (véase la tabla 2). Además del

\section{TABLA 2}

Producción y comercio de energía en 1980 y 1992

(En millones de toneladas métricas de carbón)

\begin{tabular}{|c|c|c|c|c|c|c|}
\hline \multirow{2}{*}{$\begin{array}{l}\text { Países de la cuenca } \\
\text { mediterránea }\end{array}$} & \multicolumn{3}{|c|}{ Producción } & \multicolumn{3}{|c|}{ Balanza comercial (a) } \\
\hline & 1980 & 1992 & Incremento & 1980 & 1992 & Incremento \\
\hline \multicolumn{7}{|l|}{ Norte } \\
\hline 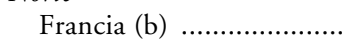 & 64,6 & 163,3 & 98,7 & $-213,0$ & $-176,3$ & 36,7 \\
\hline 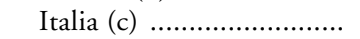 & 29,4 & 40,0 & 10,6 & $-172,8$ & $-195,1$ & $-22,3$ \\
\hline España ............................... & 22,3 & 42,6 & 20,3 & $-79,1$ & $-94,0$ & $-14,9$ \\
\hline Portugal ............................. & 1,2 & 0,7 & $-0,5$ & $-13,8$ & $-22,6$ & $-8,8$ \\
\hline 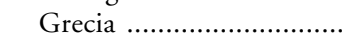 & 4,8 & 11,3 & 6,5 & $-20,1$ & $-25,4$ & $-5,3$ \\
\hline Malta $\ldots \ldots \ldots \ldots \ldots \ldots \ldots \ldots \ldots \ldots$ & $\ldots$ & $\ldots$ & $\ldots$ & $-0,6$ & $-0,8$ & $-0,2$ \\
\hline Albania ............................... & 3,6 & 1,5 & $-2,1$ & $-0,5$ & $-1,0$ & $-0,5$ \\
\hline \multicolumn{7}{|l|}{ Sur } \\
\hline Israel .................................. & 0,2 & 0,04 & $-0,16$ & $-12,0$ & $-19,9$ & $-7,9$ \\
\hline 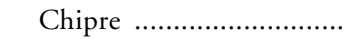 & $\ldots$ & $\ldots$ & $\ldots$ & $-1,4$ & $-2,6$ & $-1,2$ \\
\hline 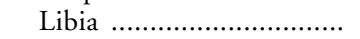 & 132,8 & 109,8 & $-23,0$ & 121,5 & 92,7 & $-28,8$ \\
\hline 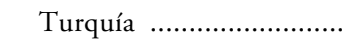 & 14,1 & 25,3 & 11,2 & $-19,9$ & $-39,3$ & $-19,4$ \\
\hline 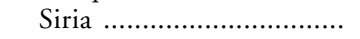 & 13,5 & 40,8 & 27,3 & 2,8 & 19,8 & 17,0 \\
\hline 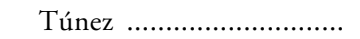 & 8,7 & 7,7 & 1,0 & 3,8 & 1,0 & $-2,8$ \\
\hline Argelia ................................ & 100,9 & 153,1 & 52,2 & 66,7 & 110,3 & 43,6 \\
\hline 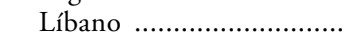 & 0,1 & 0,04 & $-0,06$ & $-3,0$ & $-5,1$ & $-2,1$ \\
\hline Marruecos ............................ & 1,0 & 0,7 & $-0,3$ & $-5,9$ & $-11,5$ & $-5,6$ \\
\hline Egipto ............................... & 46,0 & 80,7 & 34,7 & 21,0 & 36,2 & 15,2 \\
\hline
\end{tabular}

NOTAS: El volumen de producción de cualquier producto energético se expresa en una unidad de volumen de energía estándar como son millones de toneladas métricas de carbón.

(a) Exportaciones menos importaciones.

(b) Incluye Mónaco.

(c) Incluye San Marino.

Fuente: United Nations, Statistical Yearbook 1993-94 (Nueva York: United Nations, 1995), pp. 574-599. 
petróleo, las exportaciones de gas natural también juegan un papel importante. El resto de países del área no productores de petróleo (descontando a Israel y Chipre) aplican el mismo modelo fallido de desarrollo del sector secundario en otras áreas de producción, casi siempre en industria pesada. Marruecos, por ejemplo, desarrolla la industria de extracción de fosfatos y producción de elementos derivados.

La producción energética de los países del sur de la cuenca se exporta al norte. Francia, Italia y España son tres de los cinco países que importan un volumen mayor de energía de los países mediterráneos africanos. Todos los países de la orilla norte del mediterráneo muestran una balanza comercial de energía negativa, mientras que en los del sur y este, ésta acostumbra a ser positiva. Además, esos últimos son energéticamente autosuficientes. Esto se explica tanto por el lado de la producción como por el del consumo. En la Europa meridional se consume todo tipo de energía en cantidades elevadas, sea de producción autóctona o importada. En cambio en los países africanos y asiáticos se consume menos cantidad de energía, y se utiliza en su mayor parte el tipo de energía del que se tiene más abundancia, es decir petróleo y gas natural. La balanza comercial energética negativa no indica que en los países europeos no se produzca ningún tipo de energía; se produce electricidad, aunque Francia es el único país que la genera en cantidades suficientes para exportar.

Debido al interés de los gobiernos de los países mediterráneos del sur y este por modernizar la estructura económica como palanca hacia la modernidad, el sector industrial crece de manera ostensible durante la década de los setenta y la primera parte de los ochenta. A mediados de esa década y principios de la siguiente se estanca. Existen varias razones que hacen que el sector industrial de los países del sur y este de la cuenca no se desarrolle demasiado. La primera es la disminución de las inversiones dirigidas al sector debido al colapso de los precios del petróleo y al incremento del volumen de deuda externa. Los países del sur y este de la cuenca poseen economías dependientes del exterior. A finales de la década de los ochenta y principios de la de los noventa el desarrollo industrial se ve perjudicado por la recesión económica en los países industrializados de Europa, así como por la Guerra del Golfo. La segunda es que el sector industrial en esos países es rígido. La capacidad de maniobra y adaptación de la producción es limitada, por lo que muchas de las ramas de la industria se convierten en obsoletas y no son competitivas en el mercado internacional. Los países del sur y este de la cuenca exportan en volumen más en 1993 de lo que lo hacen en 1980, pero disminuye el valor de los productos que exportan al mercado internacional y aumenta el de los que importan. La tercera razón es que a veces se crean infraestructuras enormes que pronto quedan obsoletas; no existe capacidad para renovarlas, tanto desde un punto de vista económico como de conocimiento, porque no existen técnicos especializados en el propio país que sean capaces de entrenar todos los trabajadores cualificados necesarios. La última razón es que, debido a las políticas económicas de tipo socialista que se aplican en los países del sur y este de la 
cuenca después de la independencia y que implican nacionalizaciones masivas, existe un volumen elevado de empresas estatales grandes que en la mayoría de casos son deficitarias.

Argelia es un ejemplo de expansión y colapso del sector secundario. Explica lo que sucede en el resto de países del área. La idea para modernizar el país es establecer industrias pesadas enormes. Como resultado de esa política industrial se crean empresas estatales grandes que dominan los sectores clave de la industria. En 1992, más de tres cuartas partes de la producción industrial es estatal (en el resto de países del área, más de la mitad) ${ }^{6}$. A partir de la crisis económica de mediados de la década de los ochenta la industria se sumerge en una crisis estructural. La escasez de divisas no permite diversificar la producción del sector secundario, aunque tan sólo sea al nivel de crear productos derivados del petróleo. Tampoco permite que las empresas manufactureras existentes importen materias primas que son necesarias para producir. Como consecuencia, el rendimiento industrial es bajo, se trabaja a medio gas y todo ello se traduce en pérdidas importantes en el sector. No parece haber solución al problema, porque la necesidad de devolver la deuda impide invertir en mejorar la industria existente y diversificar el sector buscando áreas de producción nuevas susceptibles de atraer otros mercados. El gobierno reinvierte en un sector industrial obsoleto y poco productivo como única posibilidad de devolver la deuda externa e intentar superar la crisis industrial. Libia sufre un proceso parecido, aunque no tan extremo. El resto de países del área pueden diversificar y flexibilizar la producción industrial con mayor facilidad, pero en algunos casos fracasan y, en otros, lo que consiguen es debilitar el sector secundario creando industrias menores cuya producción representa una parte pequeña del PIB de esos países.

Marruecos, Túnez, Egipto y Siria también realizan inversiones masivas en proyectos del Estado. El punto de vista de cómo debe plantearse el desarrollo económico en el país no difiere del de Argelia o Libia ${ }^{7}$. Esos países no son tan dependientes de un solo producto, pero las fluctuaciones en los precios de

${ }^{6}$ El sector de los hidrocarburos se desarrolla durante la década de los sesenta en Argelia casi sin participación externa. A partir de la nacionalización de la industria productora de petróleo y de gas natural en 1971, la compañía estatal Sonatrach se convierte en la productora principal de combustibles fósiles. El país se encuentra atrapado en un modelo económico que supone depender de un solo sector en el mercado internacional. El gobierno argelino sigue canalizando una proporción importante de los recursos de inversión hacia el sector energético. No tiene otro remedio. El objetivo a largo plazo sigue siendo desarrollar y diversificar la estructura económica del país. Ese objetivo parece que sólo puede ser conseguido a partir de los fondos que provienen de las ganancias derivadas de la venta de petróleo y gas natural. Además, esas ganancias son la única manera que tiene el país de devolver la deuda externa. El gobierno se encuentra en un callejón sin salida. Los ingresos provenientes de la exportación de energía son reinvertidos en el sector de hidrocarburos, porque éste no dispone de los fondos necesarios para desarrollar y explotar depósitos nuevos.

7 Sólo Turquía, Israel, Chipre y el Líbano discrepan de esta manera de plantear la economía y se desarrollan a partir de un modelo más liberal. 
mercado del petróleo y sus derivados repercuten directamente en la balanza comercial de todo el área. En la práctica, los países del sur y este de la cuenca poseen economías dependientes del exterior, incluso los que no exportan hidrocarburos. Turquía es el único país del área (descontando a Israel y Chipre, que en 1980 ya tienen una industria consolidada) que tiene éxito al desarrollar un sector industrial importante y diversificado que consigue duplicar la producción industrial a lo largo de la última década y media (véase la tabla 3). Los países del norte de la cuenca mediterránea se desindustrializan, mientras sus vecinos del sur intentan industrializarse. Pero, en realidad, el sector secundario está estancado, inmerso en un proceso de disminución de mano de obra. Se pierden puestos de trabajo, aunque el volumen de producción es mayor en 1993 que en 1980, por lo que se gana en productividad.

El fracaso en el proceso de industrialización de los países del sur y este de la cuenca mediterránea tiene dos consecuencias, una negativa y otra positiva. Por un lado, se incrementa la deuda externa. Una proporción considerable de las inversiones gubernamentales en el desarrollo del sector industrial no puede ser financiada por el ahorro doméstico y se recurre al mercado internacional de capital. El fracaso económico hace que los países contraigan deudas masivas. Éste es el problema más grave con el que se enfrentan las economías de la mayoría de países del sur y este del Mediterráneo. Los países africanos y asiáticos de la cuenca utilizan la asistencia oficial para el desarrollo para pagar parte de la deuda (véase la tabla 4). Dada la proximidad entre esos países y la Unión Europea, los países europeos son los que juegan un papel predominante en la financiación de los fondos de asistencia al desarrollo ${ }^{8}$. Esos países financian parte del déficit de sus vecinos para prevenir una (supuesta y temida) invasión masiva de personas procedentes del otro lado del Mar Mediterráneo.

La otra consecuencia del fracaso en el proceso de industrialización en los países del bloque sur es el trasvase de trabajadores directamente del sector primario al terciario. Ese sector se desarrolla de manera más acelerada de lo que es previsible económicamente. La característica principal que define a las econo-

${ }^{8}$ Financian a los países del sur tanto a través de asistencia bilateral como multilateral. El Comité de Asistencia al Desarrollo (DAC) de la OCDE, que está formado por 18 países y la Comisión de la Unión Europea, es el financiador principal de los programas multilaterales de las Naciones Unidas. Israel y Egipto son una excepción en el área, puesto que, además de los fondos de la UE, también reciben un volumen importante de divisas a través de programas de asistencia bilateral financiados por los Estados Unidos. La asistencia per capita, calculada en dólares, es un indicador interesante de la importancia de los fondos de asistencia en cada país. Los cinco países del área con un PIB menor reciben entre 25 dólares per capita (en el caso de Argelia) y 65 (en el caso de Túnez). Es importante destacar que a Túnez, que es el país que recibe proporcionalmente un volumen más elevado de divisas, nunca se le recalifica el volumen de deuda. Existen tres excepciones en el área: Israel, que recibe más de 400 dólares anuales per capita, procedentes especialmente de programas de asistencia bilateral financiados por Estados Unidos; Libia, que presenta un saldo negativo de asistencia total debido a que es un país que financia los programas multilaterales de las Naciones Unidas; y Siria, que recibe un volumen de asistencia tanto bilateral como multilateral que es escaso. 


\section{TABLA 3}

Producción industrial en 1993

(Número índice 1980=100)

\begin{tabular}{|c|c|c|c|c|c|c|c|c|c|c|}
\hline \multirow[b]{2}{*}{ Paises de la cuenca mediterránea } & \multirow[b]{2}{*}{$\begin{array}{c}\text { Producción } \\
\text { industrial } \\
\text { total }\end{array}$} & \multirow[b]{2}{*}{$\begin{array}{l}\text { Industrias } \\
\text { extractivas }\end{array}$} & \multicolumn{7}{|c|}{ Industrias manufactureras } & \multirow[b]{2}{*}{ Electricidad } \\
\hline & & & Total & $\begin{array}{l}\text { Comida, } \\
\text { bebida } \\
y \text { tabaco }\end{array}$ & Textiles & $\begin{array}{l}\text { Productos } \\
\text { químicos y } \\
\text { petroliferos }\end{array}$ & $\begin{array}{l}\text { Productos } \\
\text { minerales } \\
\text { no metálicos }\end{array}$ & $\begin{array}{c}\text { Metal } \\
\text { base }\end{array}$ & $\begin{array}{l}\text { Productos } \\
\text { metálicos }\end{array}$ & \\
\hline \multicolumn{11}{|l|}{ Norte } \\
\hline 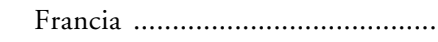 & 111 & 64 & 104 & 122 & 66 & 135 & $\ldots$ & 76 & 95 & 175 \\
\hline 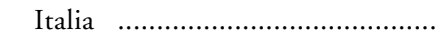 & 110 & 129 & 108 & 126 & 105 & 93 & $\ldots$ & 100 & 106 & 129 \\
\hline 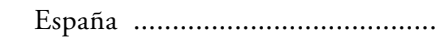 & 110 & 90 & 107 & 133 & 83 & 110 & $\ldots$ & 98 & 109 & 135 \\
\hline 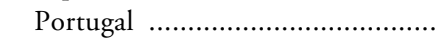 & 153 & 398 & 138 & 126 & $\ldots$ & 117 & $\ldots$ & 108 & 87 & 199 \\
\hline 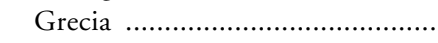 & 105 & 150 & 97 & 128 & 74 & 126 & $\ldots$ & 86 & 80 & 167 \\
\hline 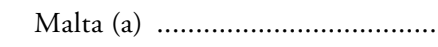 & 216 & 294 & 217 & 226 & $\ldots$ & $\cdots$ & $\ldots$ & $\ldots$ & 391 & 226 \\
\hline \multicolumn{11}{|l|}{ Sur } \\
\hline Israel (a) .................................. & 141 & 136 & 141 & 161 & 104 & 170 & $\ldots$ & 118 & 128 & $\ldots$ \\
\hline 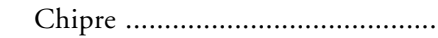 & 151 & 67 & 140 & 164 & 124 & 217 & $\ldots$ & $\ldots$ & 164 & 248 \\
\hline Turquía ...................................... & 247 & 177 & 243 & 217 & 232 & 267 & $\ldots$ & 308 & 441 & 316 \\
\hline Siria & 216 & 343 & 179 & 142 & 108 & $\ldots$ & 171 & $\ldots$ & $\ldots$ & 289 \\
\hline 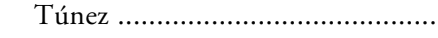 & 122 & 88 & 144 & 157 & 121 & 168 & $\ldots$ & 105 & 118 & 117 \\
\hline 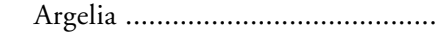 & 162 & 109 & 163 & 170 & 140 & 210 & 148 & $\ldots$ & $\ldots$ & 294 \\
\hline 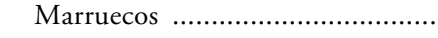 & 145 & 107 & 153 & 113 & 161 & 130 & $\ldots$ & 165 & 114 & 181 \\
\hline 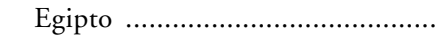 & 141 & 154 & 129 & 227 & 105 & 165 & $\ldots$ & 160 & 142 & 234 \\
\hline
\end{tabular}

(a) Datos para 1991.

FuENTE: United Nations, Statistical Yearbook 1993-94 (Nueva York: United Nations, 1995), pp. 196-218. 


\section{TABLA 4}

Deuda externa y ayuda oficial para el desarrollo en 1992

(En millones de dólares)

\begin{tabular}{|c|c|c|c|c|c|}
\hline $\begin{array}{l}\text { Paises de la cuenca } \\
\text { mediterránea }\end{array}$ & $\begin{array}{l}\text { Deuda } \\
\text { externa }\end{array}$ & $\begin{array}{c}\text { Asistencia } \\
\text { bilateral }\end{array}$ & $\begin{array}{l}\text { Asistencia } \\
\text { multilateral }\end{array}$ & $\begin{array}{l}\text { Asistencia } \\
\text { total }\end{array}$ & $\begin{array}{l}\text { Asistencia } \\
\text { per capita } \\
\text { (en dólares) }\end{array}$ \\
\hline 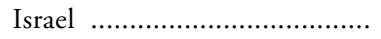 & $\ldots$ & $2.058,6$ & 7,2 & $2.065,8$ & 410,2 \\
\hline 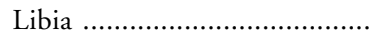 & $\ldots$ & 1,5 & $-6,8$ & $-5,3$ & $-1,1$ \\
\hline Siria & 16.234 & 50,4 & 26,3 & 76,7 & 5,8 \\
\hline 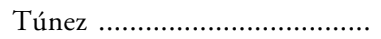 & 7.424 & 296,8 & 247,9 & 224,9 & 64,8 \\
\hline 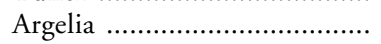 & 24.587 & 374,1 & 269,8 & 643,9 & 24,6 \\
\hline 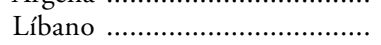 & 375 & 68,8 & 16,4 & 31,6 & 31,6 \\
\hline 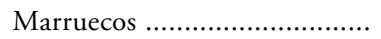 & 20.310 & 733,6 & 663,1 & $1.396,3$ & 55,0 \\
\hline 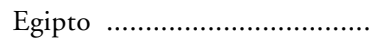 & 36.603 & $3.000,9$ & 355,1 & $3.356,0$ & 56,9 \\
\hline
\end{tabular}

FUENTE: United Nations, Statistical Yearbook 1993-94 (Nueva York: United Nations, 1995), pp. 784-798.

mías de los países mediterráneos africanos y asiáticos es que se terciarizan directamente desde el sector primario. Un fenómeno que conlleva mejoras en la calidad de vida de la población, que de esta manera evita trabajar en un sector que potencialmente ofrece salarios mínimos asociados a condiciones laborales precarias. La industria alimentaria es el sector manufacturero que aumenta de forma más sensible en la década de los ochenta y la de los noventa en los países africanos y asiáticos de la cuenca. Se consume más y mejor. Aunque desde el punto de vista económico no se percibe un gran crecimiento, sí existe una evolución social que se manifiesta en el aumento y mejora del consumo de alimentos.

\section{DEL SECTOR PRIMARIO AL TERCIARIO}

El desarrollo rápido del sector terciario en los países del sur y este de la cuenca se manifiesta de manera clara en los cambios en la distribución del sector laboral. Tanto en los países del sur como en los del norte, la proporción de personas empleadas en cada uno de los tres sectores económicos varía ostensiblemente entre 1980 y 1995 . Siendo los países africanos y asiáticos económica y socialmente diferentes de los europeos, los cambios en el mercado de trabajo se producen de manera similar en todos ellos. La consecuencia de las políticas de desarrollo industrial fracasadas es que los países del sur y este de la cuenca, igual que los del norte, traspasan trabajadores/as del sector primario directamente al terciario (de la agricultura a los servicios), y no al secundario (la industria). El sector de servicios se desarrolla a la misma velocidad en ambas orillas del Mar Mediterráneo. 
En tan sólo quince años los países de la cuenca del Mediterráneo sufren cambios importantes en la estructura del sector laboral. En 1980, la proporción de personas empleadas en cada uno de los tres sectores económicos es ostensiblemente diferente de la de 1993. Los cambios en el mercado de trabajo, que se producen de manera similar tanto en los países del norte de la cuenca mediterránea como en los del sur y este, son indicativos a la vez de desarrollo económico y de evolución social, y reflejan una mejora de la calidad de vida de las personas. En los países del sur de Europa, los movimientos del porcentaje de personas que trabajan en cada uno de los sectores son profusamente estudiados. Son consecuencia de un desarrollo de la economía que se manifiesta en un incremento importante del PIB per capita. La mejora económica repercute en la esfera de lo social. En los países africanos y asiáticos de la cuenca la evolución del mercado de trabajo es similar a la de los europeos. El incremento del PIB per capita es menor. Aunque la economía no evolucione de manera ostensible, la evolución en la estructura del mercado laboral repercute en la esfera de lo social, igual que sucede con los países del norte de la cuenca.

En 1980, la proporción de personas que trabajan en el sector agrario es el doble que en 1993 en las dos áreas de estudio. La disminución es tan importante en los países del norte de la cuenca como en los del sur y este ${ }^{9}$. Portugal, a lo largo de esos tres lustros, deja de ser un país principalmente agrario. El número de personas que trabajan en el campo se reduce en dos terceras partes. Es una de las explicaciones de que Portugal sea el país mediterráneo que incrementa proporcionalmente más el PIB per capita a lo largo de los tres últimos quinquenios. El desarrollo no es sólo económico, sino también social, de calidad de vida de las personas. Es el país de la Europa mediterránea que muestra una evolución más significativa en ese sentido. La proporción de personas trabajando en el sector agrario es uno de los índices de desarrollo social más clásicos y eficientes. España y Grecia también experimentan un proceso de pérdida de población activa en el sector primario, pero en menor escala ${ }^{10}$.

La evolución de la estructura laboral es similar en todos los países mediterráneos. La disminución de la proporción de personas en el sector primario (agrícola y ganadero) a lo largo de los quince años se compensa con un incremento de la proporción de trabajadores/as en el sector terciario (de servicios). El porcentaje de trabajadores/as en el sector secundario (industrial) se reduce tanto en los países europeos como en los africanos y asiáticos. En los países del

9 En Egipto, en 1980, casi la mitad de las personas trabajan en la agricultura; y en Grecia y Portugal, casi una tercera parte.

${ }^{10}$ Los países de la cuenca se desagrarizan tanto en el norte como en el sur. En todos ellos, excepto en dos, el porcentaje de personas del total de la población ocupada que trabajan en el sector primario disminuye. Las dos excepciones son Croacia y Albania, países históricamente comunistas del este de la Europa mediterránea y que se encuentran en plena fase de transición económica y social al sistema capitalista. Una transición que en los dos casos es difícil. En Croacia, el incremento de población ocupada en el sector primario es débil, no llega a 0,5 por 100; en Albania, en cambio, el incremento es considerable, de más del 2 por 100. 
norte de la cuenca, la disminución en el porcentaje de trabajadores industriales correlaciona con la riqueza del país. En Francia, entre 1980 y 1993, un 24 por 100 de los/as trabajadores del sector industrial pasan al de servicios; en Italia, el porcentaje es del 19 por 100; en España, del 17 por 100, y en Portugal, del 12 por 100. La industria pesada, o la industria que necesita de mano de obra barata en abundancia, se vuelve obsoleta, y cuanto más desarrollado es el país, más rápidamente desaparece ${ }^{11}$.

El sector secundario es poco importante en las economías de los países del sur y este de la cuenca, y el aumento de trabajadores es pequeño ${ }^{12}$. La tendencia más importante a lo largo de los tres quinquenios es que los países del sur y este de la cuenca, igual que los del norte, traspasan trabajadores/as del sector primario directamente al terciario, no al secundario. El sector de servicios se desarrolla a la misma velocidad en los países del sur y este de la cuenca mediterránea que en los del norte. Es un fenómeno sorprendente si se tiene en cuenta que la estructura económica de unos y otros es absolutamente diferente. En los países africanos y asiáticos de la cuenca se produce un trasvase de trabajadores/as directamente de la agricultura a los servicios. La economía en esos países evoluciona de manera distinta a los países europeos. El desarrollo es más rápido porque se salta un eslabón; prácticamente no hay desarrollo industrial. El proceso de transformación de la economía no se produce de la manera habitual, de la agricultura a la industria y de la industria a los servicios. Es un desarrollo diferente que es más significativo a nivel social que a nivel económico. Al ser un desarrollo atípico, es poco perceptible si sólo se analiza desde un punto de vista economicista. En muchos casos resulta invisible para los/as economistas.

En 1980 trabaja un porcentaje mayor de personas en los países del norte de la cuenca mediterránea que en los del sur y este. Descontando a Albania, donde el porcentaje de personas que trabajan del total de la población no llega a una cuarta parte, en el resto de países de la Europa mediterránea el porcentaje de población en el mercado laboral va desde un 40 por 100 en Francia a un 31 por 100 en España. En los países asiáticos y africanos los datos fluctúan entre un 32 por 100 en Israel y Chipre, y un 15 por 100 en Siria (tabla 5). La proporción de varones trabajando del total de la población (masculina) es parecido en todos los países mediterráneos independientemente de cuál sea el

${ }^{11}$ La disminución de trabajadores en el sector secundario no sólo afecta a la industria, sino también a la construcción.

${ }^{12}$ En los países del sur y este de la cuenca, la disminución de trabajadores/as en el sector secundario a lo largo de los tres lustros no correlaciona con la riqueza, como sucede en el norte. El único país de los que se tienen datos en el que el porcentaje de personas trabajando en industria no disminuye, sino que aumenta, es Egipto. En ese país, así como en Turquía, Marruecos y Túnez, se produce un incremento ligero en el sector industrial. Un sector que históricamente es poco relevante en la economía de esos países. En los últimos tres lustros se desarrollan ligeramente las industrias textiles y alimentarias. Esta tendencia deriva de la necesidad de mano de obra barata que tienen las industrias en esos sectores. En muchos casos, la producción a partir de mano de obra no especializada se obtiene en la economía sumergida. 


\section{TABLA 5}

Evolución de la proporción de población activa, por género (En porcentajes)

\begin{tabular}{|c|c|c|c|c|c|c|c|c|c|}
\hline \multirow{2}{*}{$\begin{array}{l}\text { Paises de la cuenca } \\
\text { mediterránea }\end{array}$} & \multicolumn{3}{|c|}{ Personas que trabajan en 1980} & \multicolumn{3}{|c|}{ Personas que trabajan en 1993} & \multicolumn{3}{|c|}{$\begin{array}{c}\text { Incremento del porcentaje de personas } \\
\text { que trabajan entre } 1980 \text { y } 1993\end{array}$} \\
\hline & Total & Varones & Mujeres & Total & Varones & Mujeres & Total & Varones & Mujeres \\
\hline \multicolumn{10}{|l|}{ Norte } \\
\hline Francia $\ldots \ldots \ldots \ldots \ldots \ldots \ldots \ldots \ldots \ldots \ldots \ldots \ldots \ldots$ & 40,4 & 49,4 & 31,6 & 39,0 & 43,8 & 33,4 & $-1,4$ & $-5,6$ & 1,8 \\
\hline 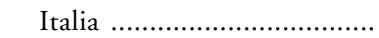 & 36,5 & 50,0 & 23,0 & 37,8 & 49,0 & 26,6 & 1,3 & $-1,0$ & 3,6 \\
\hline España ................................ & 31,0 & 44,4 & 17,6 & 30,3 & 40,2 & 20,5 & $-0,7$ & $-4,2$ & 2,9 \\
\hline Portugal ............................... & 40,0 & 49,0 & 31,1 & 45,5 & 50,7 & 40,2 & 5,5 & 1,7 & 10,1 \\
\hline 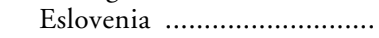 & $\ldots$ & $\ldots$ & $\ldots$ & 40,3 & 42,4 & 38,2 & $\ldots$ & $\ldots$ & $\ldots$ \\
\hline 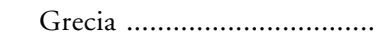 & 36,5 & 50,0 & 22,9 & 35,6 & 46,2 & 25,0 & $-0,9$ & $-3,8$ & 2,1 \\
\hline Malta ............................... & 32,8 & 54,4 & 17,2 & 38,2 & 56,5 & 20,0 & 5,4 & 2,1 & 2,8 \\
\hline Croacia ............................ & & $\ldots$ & $\ldots$ & 25,8 & 28,4 & 23,1 & $\ldots$ & $\ldots$ & $\ldots$ \\
\hline Albania ................................. & 24,4 & 29,4 & 19,4 & 25,0 & 29,0 & 20,9 & 0,6 & $-0,4$ & 1,5 \\
\hline \multicolumn{10}{|l|}{ Sur } \\
\hline 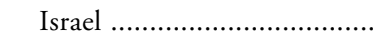 & 32,1 & 41,1 & 23,2 & 32,4 & 38,3 & 26,6 & 0,3 & $-2,8$ & 3,4 \\
\hline Chipre ............................... & 32,2 & 41,0 & 23,3 & 45,2 & 54,7 & 35,7 & 13,0 & 13,7 & 12,5 \\
\hline Turquía .............................. & $\ldots$ & $\ldots$ & $\ldots$ & 31,6 & 43,6 & 19,6 & $\ldots$ & $\ldots$ & $\ldots$ \\
\hline 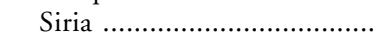 & 15,4 & 26,5 & 4,3 & 23,6 & 39,3 & 7,8 & 8,2 & 12,8 & 3,5 \\
\hline Marruecos ............................. & $\ldots$ & $\ldots$ & $\ldots$ & 13,1 & 20,6 & 5,7 & $\ldots$ & $\ldots$ & $\ldots$ \\
\hline 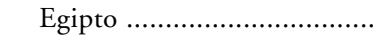 & 23,2 & 42,8 & 3,3 & 23,2 & 37,8 & 9,9 & 0,0 & $-5,0$ & 6,6 \\
\hline
\end{tabular}

FuENTE: United Nations, Statistical Yearbook 1993-94 (Nueva York: United Nations, 1995), pp. 236-246. 
porcentaje total de población en el mercado laboral ${ }^{13}$. Lo que marca la diferencia entre un país con una proporción alta de población en el mercado laboral y uno con una proporción baja es el porcentaje de mujeres trabajadoras. Los países con porcentajes altos de personas en el mercado de trabajo - como es el caso de Francia y Portugal, que tienen el 40 por 100 de población trabajadora - tienen porcentajes altos de mujeres en el mercado laboral. En Francia y en Portugal trabaja más de un 31 por 100 de población femenina. En España o Malta, que son países de porcentajes bajos de personas activas, tan sólo un 17 por 100 de la población femenina trabaja. Existe el caso extremo de Egipto, con un 23 por 100 de población incorporada al mercado laboral que prácticamente son todos varones ${ }^{14}$. A lo largo de los tres lustros estudiados, el porcentaje de mujeres en el mercado de trabajo incrementa en todos los países del Mediterráneo, tanto en los de la orilla norte como en los de las orillas sur y este. En 1993, la proporción de población en el mercado laboral es más homogénea que en 1980. La convergencia entre géneros en la proporción de población ocupada es relevante en los países del sur y este de la cuenca ${ }^{15}$.

En los países del Mediterráneo trabaja una proporción mayor de varones que de mujeres. El promedio de mujeres que trabajan por cada cien varones en los países del norte de la cuenca mediterránea es casi el doble que en los del sur y el este. En los países europeos de la cuenca trabajan de media 59 mujeres por cada cien varones; y en los africanos y asiáticos, 34. La diferencia es considerable entre las dos áreas, pero también es elevada entre los países que conforman cada una de ellas. Los países de la Europa mediterránea que muestran una proporción más alta de mujeres que trabajan son los del este (las antiguas Repúblicas yugoslavas y Albania). En Eslovenia, por cada cien varones trabajan 90 mujeres; en Croacia, 81, y en Albania, 72. En la tabla 6 se observa que los países de la Europa mediterránea que poseen una proporción menor de mujeres en el mercado laboral respecto a los varones son los más meridionales: España, donde sólo trabajan 51 mujeres por cada cien varones; Italia, con 54 por cada cien; Grecia, 53, y la isla de Malta, que tiene el porcentaje de mujeres en el mercado laboral más bajo de la Europa mediterránea, con tan sólo 34 mujeres por cada cien varones. En Turquía hay 45 mujeres trabajando en el mercado laboral por cada cien varones. Sin que llegue a superar la proporción de muje-

${ }^{13}$ El porcentaje de varones trabajadores del total de varones de la población es superior al 40 por 100 en todos los países de la cuenca mediterránea excepto en Albania (29 por 100) y Siria (26 por 100).

${ }_{14}$ Las cifras proporcionadas por el Statistical Yearbook de las United Nations indican que en Egipto un 43 por 100 de los varones trabajan, mientras que el porcentaje de mujeres en el mercado de trabajo es tan sólo del 3 por 100.

15 Tan sólo Marruecos, que tiene un 13 por 100 de la población trabajando, se diferencia de manera clara de las proporciones que presentan los países de la Europa mediterránea. A pesar de ese porcentaje bajo de personas en el mercado laboral, Marruecos es un país económicamente activo; tiene un mercado interno importantes. El sector agrario y manufacturero (especialmente de productos textiles) tiene importancia. Esto da una imagen clara de que en Marruecos existe un volumen elevado de economía sumergida en la que trabajan principalmente mujeres. 


\section{TABLA 6}

Población activa según sector económico y género en 1993

(En porcentajes de población trabajadora)

\begin{tabular}{|c|c|c|c|c|c|c|c|c|c|c|c|c|c|c|c|c|c|c|c|c|}
\hline \multirow[b]{2}{*}{$\begin{array}{c}\text { Paises de la cuenca } \\
\text { mediterránea }\end{array}$} & \multicolumn{2}{|c|}{$\begin{array}{c}\text { Total } \\
\text { (en miles) }\end{array}$} & \multicolumn{2}{|c|}{ Agricultura } & \multicolumn{2}{|c|}{$\begin{array}{l}\text { Industrias } \\
\text { extrac- } \\
\text { tivas }\end{array}$} & \multicolumn{2}{|c|}{$\begin{array}{l}\text { Manu- } \\
\text { facturas }\end{array}$} & \multicolumn{2}{|c|}{$\begin{array}{l}\text { Electricidad, } \\
\text { gas } \\
\text { y agua }\end{array}$} & \multicolumn{2}{|c|}{$\begin{array}{l}\text { Construc- } \\
\text { ción }\end{array}$} & \multicolumn{2}{|c|}{$\begin{array}{c}\text { Comercios } \\
y \\
\text { hosteleria }\end{array}$} & \multicolumn{4}{|c|}{$\begin{array}{l}\text { Transportes Finanzas, } \\
\text { yalmace- seguros e in- } \\
\text { namiento mobiliarias }\end{array}$} & \multicolumn{2}{|c|}{ Servicios } \\
\hline & $M$ & $\begin{array}{l}\text { Mpor } \\
100 \mathrm{~V}\end{array}$ & $V$ & $M$ & $V$ & $M$ & $V$ & $M$ & $V$ & $M$ & $V$ & $M$ & $V$ & $M$ & $V$ & $M$ & $V$ & $M$ & $V$ & $M$ \\
\hline \multicolumn{21}{|l|}{ Norte } \\
\hline Francia (a) (c) .. & 9.644 & 76 & 6,2 & 3,9 & $\ldots$ & $\ldots$ & 37,8 & 16,1 & $\cdots$ & $\ldots$ & $\ldots$ & $\ldots$ & 56,0 & 80,0 & $\cdots$ & $\ldots$ & $\ldots$ & $\cdots$ & $\ldots$ & $\ldots$ \\
\hline Italia (a) ................... 14.021 & 7.588 & 54 & 7,9 & 8,5 & 1,5 & 0,3 & 22,7 & 19,8 & $\ldots$ & $\ldots$ & 13,0 & 1,4 & 20,6 & 22,7 & 6,9 & 2,4 & 4,6 & 5,8 & 22,8 & 32,0 \\
\hline España ........................ 7.850 & 3.987 & 51 & 11,1 & 8,2 & 0,7 & $\ldots$ & 21,9 & 13,6 & 0,9 & 0,2 & 13,3 & 1,0 & 20,3 & 26,5 & 7,7 & 2,2 & 7,1 & 9,3 & 15,1 & 37,8 \\
\hline Portugal .................... 2.486 & 1.971 & 79 & 9,5 & 12,8 & 0,8 & $\cdots$ & 24,1 & 22,5 & 1,0 & 0,3 & 7,2 & 0,8 & 20,0 & 18,7 & 6,5 & 2,4 & 7,3 & 6,0 & 15,7 & 36,4 \\
\hline Eslovenia ................... 403 & 363 & 90 & 8,1 & 5,1 & 2,2 & $\ldots$ & 43,2 & 35,0 & 2,3 & 0,7 & 7,4 & 1,2 & 7,4 & 15,0 & 8,1 & 2,9 & 3,6 & 5,3 & 17,8 & 29,0 \\
\hline Grecia (a) .................. 2.403 & 1.281 & 53 & 19,5 & 26,4 & 0,7 & $\ldots$ & 20,3 & 16,5 & 1,3 & 0,4 & 10,1 & 0,3 & 17,6 & 20,6 & 9,2 & 2,3 & 5,0 & 6,3 & 16,3 & 27,2 \\
\hline Malta (b) .................... & 34 & 36 & 3,0 & 1,2 & 0,6 & $\ldots$ & 26,0 & 31,8 & 1,9 & 0,3 & 6,0 & 0,3 & 10,3 & 10,8 & 8,8 & 3,2 & 3,0 & 6,1 & 40,5 & 46,4 \\
\hline Croacia (a) .................. & 519 & 81 & 7,2 & 3,0 & 1,1 & 0,2 & 35,4 & 31,4 & 3,6 & 1,0 & 10,8 & 2,0 & 12,0 & 20,4 & 12,6 & 4,6 & 2,4 & 4,9 & 14,7 & 32,6 \\
\hline Albania (b) ..................... & 356 & 72 & 21,7 & 24,7 & $\ldots$ & $\ldots$ & 30,6 & 39,6 & $\ldots$ & $\ldots$ & 14,1 & 1,8 & 5,6 & 8,3 & 6,5 & 1,8 & 2,3 & 3,9 & 18,9 & 19,9 \\
\hline \multicolumn{21}{|l|}{ Sur } \\
\hline Israel ........................... 1.033 & 718 & 70 & 4,7 & 1,9 & $\ldots$ & $\ldots$ & 26,2 & 14,0 & 1,4 & 0,4 & 10,8 & 0,9 & 14,3 & 14,4 & 7,9 & 3,5 & 9,4 & 12,2 & 24,7 & 52,5 \\
\hline Chipre .......................... 164 & 107 & 65 & 11,8 & 14,7 & 0,4 & $\ldots$ & 15,3 & 19,2 & 0,8 & 0,1 & 13,4 & 1,3 & 22,8 & 28,6 & 7,4 & 3,8 & 6,3 & 8,5 & 20,2 & 23,0 \\
\hline Turquía ..................... 13.348 & 5.990 & 45 & 30,2 & 73,6 & 1,1 & $\ldots$ & 16,9 & 10,8 & 0,8 & 0,1 & 8,4 & 0,3 & 17,2 & 3,1 & 6,7 & 1,0 & 2,7 & 1,9 & 16,1 & 9,2 \\
\hline Siria (b) .................... 2.710 & 540 & 20 & 23,9 & 54,1 & 0,2 & $\ldots$ & 15,5 & 6,4 & 0,4 & 0,1 & 12,3 & 1,2 & 13,6 & 1,7 & 5,8 & 1,6 & 0,7 & 0,8 & 28,3 & 34,8 \\
\hline Marruecos (a) .............. 2.734 & 761 & 28 & 3,8 & 2,8 & 1,6 & 0,2 & 20,1 & 44,8 & 1,1 & 0,3 & 10,2 & 0,5 & 25,5 & 8,2 & 6,9 & 1,4 & 1,9 & 3,1 & 28,5 & 38,5 \\
\hline Egipto (b) .................. 10.972 & 2.855 & 26 & 29,4 & 38,9 & 0,3 & $\ldots$ & 16,2 & 12,4 & 1,1 & 0,5 & 9,3 & 3,9 & 11,4 & 8,1 & 9,0 & 3,5 & 3,2 & 2,5 & 20,2 & 30,1 \\
\hline
\end{tabular}

NOTAS: (a) Son datos para 1992.
(b) Son datos para 1991.
(c) Se indica el porcentaje de trabajadores por sector económico (primario, secundario y terciario) y no por actividad económica.
$\mathrm{V}=$ Varones; $\mathrm{M}=$ Mujeres.

FUENTE: United Nations, Statistical Yearbook 1993-94 (Nueva York: United Nations, 1995), pp. 236-246. 
res trabajadoras mostrada por los países de la Europa mediterránea, el porcentaje de mujeres en el mercado laboral turco es alto si se tiene en cuenta que es un país de población mayoritariamente musulmana. Tradicionalmente, la mujer en el Islam no trabaja fuera del hogar. Esa proporción alta se explica por las características especiales de Turquía desde que Kemal Ataturk, en 1923, concede a las mujeres igualdad de derechos y basa la ley turca en modelos occidentales. En Siria, Marruecos y Egipto hay menos de treinta mujeres por cada cien varones trabajando en el mercado laboral.

Entre 1980 y 1993, en los países africanos y asiáticos se incorporan proporcionalmente más mujeres al mercado de trabajo que en los países de la Europa mediterránea. Aunque en 1993 esos países siguen teniendo un porcentaje bastante más bajo de mujeres trabajadoras que los del norte de la cuenca. La escolarización de mujeres correlaciona con el incremento del porcentaje de mujeres que se integra al mercado laboral de los países del sur y este de la cuenta. Desde 1980 la escolarización en primaria es prácticamente universal en los países africanos y asiáticos de la cuenca, y en la década de los noventa los porcentajes de escolarización en secundaria empiezan a acercarse a los de la Europa mediterránea. Esa escolarización viene acompañada de una disminución de la discriminación por género que tradicionalmente se produce en educación. Una tendencia que empieza a manifestarse con la incorporación de las mujeres en el mercado de trabajo de los países africanos y asiáticos del Mediterráneo. En tan sólo tres lustros, la proporción de mujeres trabajadoras se duplica en Siria y se triplica en Egipto. En los países islámicos se está creando una generación de mujeres jóvenes que han sido educadas en la escuela y que se incorporan al mercado laboral ${ }^{16}$. Los países islámicos del sur y el este del Mediterráneo, así como los países más meridionales de la Europa mediterránea (España, Italia y Grecia), poseen una economía sumergida extensa. Una parte importante de los trabajos en el mercado negro están ocupados por mujeres. En muchos casos la mujer trabaja en el propio hogar.

En los países mediterráneos el número de mujeres incorporadas al mercado laboral aumenta en un 10 por 100 entre 1980 y 1994 . El avance más importante es el de Egipto, donde en 1980 tan sólo trabajan ocho mujeres por cada cien varones y en 1994 ya son 26. Los países de la Europa mediterránea van un paso por delante respecto de los africanos y asiáticos en el desarrollo de la estructura del mercado laboral femenino. A lo largo de los tres últimos quinquenios, una proporción alta de mujeres trabajadoras en la Europa mediterránea abandonan los trabajos duros en cadenas de montaje, en industria manufacturera intensiva en mano de obra y en industrias pesadas para pasar al sector terciario. Por el contrario, en los países africanos y asiáticos las mujeres abandonan su trabajo en el campo y empiezan a trabajar en industrias manufacture-

${ }_{16}$ Es una muestra más de ese «desarrollo invisible» o inmaterial que se puede medir en la región. Es un desarrollo que debe ser analizado desde un punto de vista sociológico — como en este caso el de la discriminación por género- más que desde un punto de vista económico. 
ras intensivas en mano de obra, en cadenas de montaje e incluso en industria pesada. Durante el mismo período de tiempo, las mujeres del norte abandonan los trabajos en los que las del sur ingresan. A pesar de ello, en los países islámicos que la mujer pueda trabajar fuera del hogar supone una revolución social importante y el reflejo de cambios acelerados en la estructura familiar. La mujer trabajadora tiene más bienes, derechos y prestigio social; en muchos casos puede reivindicar con más fuerza su importancia en la estructura familiar, así como la de sus hijas. En condiciones sanitarias iguales, las tasas de mortalidad perinatal e infantil en niños son siempre mayores que las de las niñas. Sin embargo, hasta finales de la década de los ochenta, en varios países musulmanes de la cuenca morían más niñas menores de cuatro años que niños. En esos casos es posible presumir desigualdades por género en el trato sanitario, no sólo por parte de las instituciones sanitarias, sino sobre todo por parte de las familias. Que en la década de los noventa la estructura por género de mortalidad infantil y perinatal de los países del sur y este de la cuenca sea parecida a la de los del norte puede ser atribuido, en parte, al incremento del volumen de mujeres en el mercado laboral y la consiguiente mejora de estatus social.

En 1993, la distribución de trabajadores/as según sectores económicos es parecida entre los países del norte de la cuenca y los del sur y este. Tal como se muestra en la tabla 7 , la única diferencia significativa es que los países africanos y asiáticos tienen un porcentaje de trabajadores/as más alto que los europeos trabajando en el sector primario, sobre todo en agricultura. Esa proporción un poco más alta de personas trabajando en el sector primario se compensa por proporciones ligeramente más bajas tanto en el sector secundario como en el terciario. En Italia, Francia y España, la producción agraria representa un porcentaje del PIB más importante que en los países asiáticos o africanos del Mediterráneo. Los tres países son productores y exportadores a gran escala de productos agrarios a todo el mundo. En esos países se realiza una agricultura especializada y, sobre todo, mecanizada. En los países del sur y el este de la cuenca mediterránea se efectúa un tipo de producción agraria que es más intensiva en trabajo manual ${ }^{17}$. Los dos únicos países de la Europa mediterránea con una proporción de población empleada importante trabajando en el sector primario son Grecia y Albania, que a mediados de los noventa tienen casi una cuarta parte de los/as trabajadores dedicados a tareas agrarias. Esa pro-

17 Francia, a pesar de ser uno de los mayores productores agrarios de la Comunidad Europea, tiene un porcentaje bajo (del 5 por 100) de personas que trabajan en el sector primario. Italia, España y Portugal también son productores importantes de productos agrícolas, y aunque el porcentaje de personas empleadas del total que trabaja en el sector primario es mayor que en Francia (9, 11 y 12 por 100 , respectivamente), es aún proporcionalmente bajo si se tiene en cuenta el volumen de producción. El país mediterráneo con un proporción menor de personas empleadas en el sector primario es la isla de Malta. Eslovenia y Croacia también tienen porcentajes bajos de población trabajando en agricultura. Los países de tradición comunista son más industriales que agrarios. 
TABLA 7

Evolución de la población empleada según sector económico, 1980-1993

(En porcentajes del total de población empleada)

\begin{tabular}{|c|c|c|c|c|c|c|c|c|c|c|c|c|}
\hline \multirow[b]{2}{*}{ Paises de la cuenca mediterránea } & \multicolumn{3}{|c|}{ Total (en millones) } & \multicolumn{3}{|c|}{ Sector primario } & \multicolumn{3}{|c|}{ Sector secundario } & \multicolumn{3}{|c|}{ Sector terciario } \\
\hline & 1980 & 1993 & $\begin{array}{c}\% \text { incre- } \\
\text { mento }\end{array}$ & 1980 & 1993 & $\begin{array}{c}\% \text { incre- } \\
\text { mento }\end{array}$ & 1980 & 1993 & $\begin{array}{c}\% \text { incre- } \\
\text { mento }\end{array}$ & 1980 & 1993 & $\begin{array}{c}\% \text { incre- } \\
\text { mento }\end{array}$ \\
\hline \multicolumn{13}{|l|}{ Norte } \\
\hline Francia & 21,7 & 22,3 & 2,5 & 8,4 & 5,2 & $-3,2$ & 35,4 & 29,4 & $-7,0$ & 56,2 & 66,4 & 10,2 \\
\hline 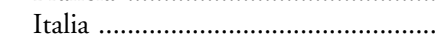 & 20,7 & 21,6 & 4,5 & 15,1 & 9,2 & $-5,9$ & 36,2 & 30,6 & $-5,6$ & 48,7 & 60,2 & 11,5 \\
\hline 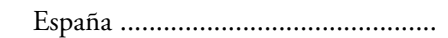 & 11,6 & 11,8 & 2,4 & 20,1 & 10,6 & $-9,5$ & 35,2 & 30,2 & $-5,0$ & 44,7 & 59,2 & 14,5 \\
\hline 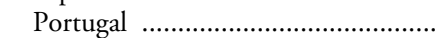 & 4,0 & 4,5 & 12,5 & 27,9 & 12,0 & $-15,9$ & 36,0 & 32,3 & $-3,7$ & 36,1 & 55,7 & 19,6 \\
\hline Eslovenia & 0,91 & 0,77 & $-18,5$ & 10,8 & 7,9 & $-2,9$ & 51,1 & 47,9 & $-3,2$ & 38,1 & 44,2 & 6,1 \\
\hline Grecia & 3,5 & 3,7 & 4,3 & 31,2 & 22,4 & $-8,8$ & 28,5 & 26,6 & $-1,9$ & 40,3 & 51,0 & 10,7 \\
\hline Malta & 0,12 & 0,13 & 10,2 & 7,1 & 3,0 & $-4,1$ & 37,4 & 33,2 & $-4,2$ & 55,5 & 63,8 & 8,3 \\
\hline 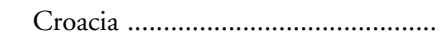 & 1,4 & 1,2 & $-22,3$ & 5,6 & 6,0 & 0,4 & 47,2 & 42,8 & $-4,4$ & 47,2 & 51,2 & 4,0 \\
\hline Albania ...................................... & 0,66 & 0,85 & 28,8 & 20,9 & 22,9 & 2,0 & 45,6 & 43,4 & $-2,2$ & 33,5 & 33,7 & 0,2 \\
\hline \multicolumn{13}{|l|}{ Sur } \\
\hline 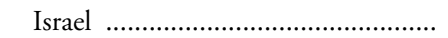 & 1,3 & 1,8 & 39,2 & 6,5 & 3,5 & $-2,8$ & 31,8 & 29,5 & $-2,3$ & 61,9 & 67,0 & 5,1 \\
\hline Chipre & 0,19 & 0,27 & 40,8 & 20,1 & 13,2 & $-6,9$ & 35,1 & 27,2 & $-7,9$ & 44,8 & 59,6 & 14,8 \\
\hline 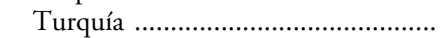 & $\ldots$ & 19,3 & $\ldots$ & $\ldots$ & 44,4 & $\ldots$ & $\ldots$ & 21,0 & $\ldots$ & $\ldots$ & 34,6 & $\ldots$ \\
\hline 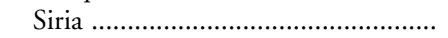 & 2,1 & 3,2 & 52,9 & 31,0 & 28,4 & $-2,6$ & 28,9 & 24,8 & $-4,1$ & 40,1 & 46,8 & 6,7 \\
\hline Marruecos & $\ldots$ & 3,5 & $\ldots$ & $\ldots$ & 4,9 & $\ldots$ & $\ldots$ & 34,7 & $\ldots$ & $\ldots$ & 60,4 & $\ldots$ \\
\hline Egipto & 9,8 & 13,8 & 41,1 & 42,6 & 31,6 & $-11,0$ & 21,7 & 24,6 & 2,9 & 35,7 & 43,8 & 8,1 \\
\hline
\end{tabular}

FuENTE: United Nations, Statistical Yearbook 1993-94 (Nueva York: United Nations, 1995), pp. 236-245. 
porción es alta, aunque menor que Egipto en el sur, donde casi la mitad de la población se dedica a la agricultura; o Turquía y Siria en el este, con porcentajes de trabajadores agrarios que se acercan a un tercio de la población empleada $^{18}$.

En las economías modernas, el sector terciario (el de servicios) es siempre el más desarrollado. En el norte de la cueca mediterránea, excepto en Eslovenia (44 por 100) y en Albania (34 por 100), todos los países tienen más de la mitad de la población ocupada empleada en ese sector. En Francia, esa proporción llega a ser de dos terceras partes de las personas que trabajan. En el sur, si se exceptúa a Israel y Chipre, que son los países con economías parecidas a las de los países europeos de la cuenca, el porcentaje de trabajadores/as ocupados en el sector de servicios es inferior al 50 por 100 del total. Sin embargo, esa proporción incrementa de manera acelerada. Entre 1980 y 1995 los países africanos y asiáticos de la cuenca se desagrarizan; se produce un éxodo campo/ciudad que es importante en volumen. Las personas emigradas a las ciudades trabajan más en el sector servicios que en el industrial, debido a que ese último es minoritario en la mayoría de países. En los países del sur y este de la cuenca no se produce el ciclo normal: agricultura/industria/servicios. Las personas pasan directamente del campo al sector de servicios, saltándose el eslabón que representa la industria. Ésa es una de las explicaciones de por qué paralelamente a un desarrollo económico lento se produce un desarrollo social acelerado que es invisible para los economistas.

La evolución del sistema económico de los países del sur y este de la cuenca directamente desde el sector primario al terciario, sin que se consolide el sector secundario, mejora la calidad de vida de las personas. Una parte importante de la población pasa de desarrollar una agricultura de supervivencia en condiciones adversas a trabajar en las ciudades en empleos que, aunque mayoritariamente son precarios, ofrecen un mínimo de estabilidad económica. En valores absolutos, el producto interior bruto de los países del sur y este de la cuenca casi se duplica a lo largo de la década de los ochenta y la mitad de los noventa. La diferencia entre el aumento del PIB per capita de los países africanos y asiáticos del Mediterráneo y el de los europeos no es tan grande como parece porque la natalidad es mayor en el sur que en el norte y las tasas de incremento de la población son altas. Un incremento general del PIB en los

18 Las Naciones Unidas ofrecen datos sorprendentes sobre la población que se dedica al sector agrario en Marruecos. Ese país tiene la proporción más baja de personas trabajando en agricultura de todos los del Mediterráneo. Marruecos, junto con Argelia y Egipto, son los tres países del sur y este del Mediterráneo que tienen un sector agrario más importante. Además, Marruecos es el país africano que exporta más cantidad de frutas, aceitunas y aceite de oliva al resto del mundo. Es improbable, por no decir imposible, que sea tan baja la proporción de personas que trabajan en el sector agrario. Otro dato sorprendente aportado por las Naciones Unidas es que en 1993 la proporción de población en el mercado laboral en Marruecos es tan sólo un 13 por 100. Esos dos datos indican que seguramente en las estadísticas marroquíes no se tiene en cuenta las personas que trabajan en el sector agrario muchas veces por cuenta propia. 
países africanos y asiáticos repercute tanto o más en la calidad de vida de las personas que un incremento del PIB per capita importante en los países europeos debido a efectos de sinergia positivos. El valor social de un hospital o una escuela nuevos es mayor que su coste dividido por el total de usuarios/as. Además, los países del sur y este de la cuenca no sufren el fenómeno de la hiperinflación, que es frecuente en otros países en vías de desarrollo. Una inflación elevada significa siempre un deterioro en la calidad de vida de la mayoría de las personas, que pierden capacidad de consumo. La inflación en los países del sur y del este de la cuenca mediterránea es moderada, similar a la de los países que conforman la Europa mediterránea.

\section{DESARROLLO SOCIAL Y NUEVO CONSUMO DE BIENES Y SERVICIOS}

Una manera de medir la evolución del bienestar de la población es a partir del consumo. A mediados de la década de los noventa, en todos los países africanos y asiáticos de la cuenca se consume más y mejor que a principios de los ochenta. Las mejoras en la calidad de vida también son contrastables comparando el consumo que realiza la población de los países que conforman las orillas de la cuenca mediterránea. El incremento del volumen de bienes consumidos en el sur es importante en todo tipo de productos, aunque las desigualdades con los países de la ribera norte de la cuenca son más importantes cuando el producto no es de consumo básico. Los bienes básicos para la supervivencia de la población están cubiertos; se consume la misma cantidad de calorías en el sur que en el norte. Además, la provisión de energía en los países más meridionales de la cuenca es suficiente. Los/as mediterráneos africanos y asiáticos no pasan hambre, viven en hogares confortables, pero el consumo de bienes de consumo simbólicos como televisores, teléfonos o automóviles es bastante menor que en Europa meridional.

Las disponibilidades alimentarias en los países que conforman la cuenca mediterránea es uno de los mejores indicadores de calidad de vida. La comida es la primera necesidad de la población que debe ser cubierta. Pasar hambre no implica vivir mejor o peor, implica no poder vivir. En la tabla 8 se presentan los datos de cantidad de comida per capita en términos de nutrientes como son las calorías y las proteínas. Se representa la media de las disponibilidades alimentarias de la población en conjunto. Ese promedio es diferente del consumo individual de las personas. El consumo es distinto para cada persona y hogar. Que la media de consumo individual en el país sea suficiente no quiere decir que ciertas personas o estratos sociales no pasen hambre o sufran escaseces. A pesar de todo, es un indicador excelente para observar si la escasez de alimentos es generalizada.

En ningún país de la cuenca la población pasa hambre de manera generalizada. Ya desde inicios de la década de los ochenta, casi no existe diferencia 


\section{TABLA 8}

Disponibilidades alimentarias en 1980 y 1990

\begin{tabular}{|c|c|c|c|c|c|}
\hline \multirow{3}{*}{$\begin{array}{c}\text { Paises de la cuenca } \\
\text { mediterránea }\end{array}$} & \multicolumn{3}{|c|}{ Calorías } & & \\
\hline & \multicolumn{2}{|c|}{ Total en unidades } & \multirow{2}{*}{$\begin{array}{l}\text { Porcentaje } \\
\text { de la cantidad } \\
\text { requerida por } \\
\text { una persona } \\
\text { en } 1980 \text { (a) }\end{array}$} & \multicolumn{2}{|c|}{$\begin{array}{l}\text { Proteinas por persona } \\
\text { y día (en gramos) }\end{array}$} \\
\hline & 1980 & 1990 & & 1980 & 1990 \\
\hline \multicolumn{6}{|l|}{ Norte } \\
\hline 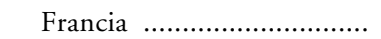 & 3.431 & 3.618 & 134 & 109 & 113 \\
\hline 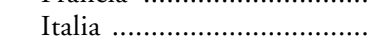 & 3.588 & 3.484 & 148 & 108 & 107 \\
\hline 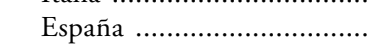 & 3.268 & 3.494 & 136 & 96 & 101 \\
\hline Portugal ................................ & 2.929 & 3.420 & 128 & 78 & 98 \\
\hline 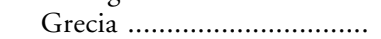 & 3.347 & 3.778 & 147 & 104 & 112 \\
\hline 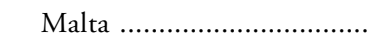 & 2.951 & 3.148 & 124 & 92 & 90 \\
\hline Albania .................................. & 2.755 & 2.392 & 110 & 85 & 74 \\
\hline \multicolumn{6}{|l|}{ Sur } \\
\hline 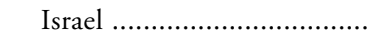 & 2.978 & 3.240 & 118 & 100 & 103 \\
\hline 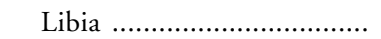 & 3.474 & 3.353 & 147 & 88 & 80 \\
\hline 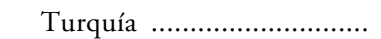 & 3.044 & 3.262 & 120 & 86 & 86 \\
\hline 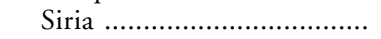 & 2.923 & 3.107 & 117 & 78 & 82 \\
\hline 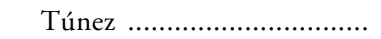 & 2.829 & 3.169 & 116 & 78 & 83 \\
\hline 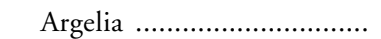 & 2.639 & 2.989 & 101 & 67 & 76 \\
\hline 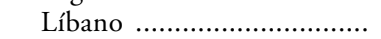 & 2.695 & 3.160 & 100 & 76 & 82 \\
\hline Marruecos ……........................ & 2.688 & 3.052 & 109 & 71 & 82 \\
\hline 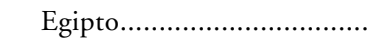 & 3.082 & 3.318 & 118 & 76 & 84 \\
\hline
\end{tabular}

NOTAS: Los datos de la cantidad de comida per capita se expresan en términos de nutrientes como son las calorías y las proteínas. Se representa la media de las disponibilidades alimentarias de la población en conjunto; no tiene por qué coincidir con el consumo individual de las personas.

(a) El porcentaje de calorías respecto de la cantidad requerida por una persona es el que se consume de media en un país respecto al volumen de energía que se considera adecuado para cubrir las necesidades energéticas de una persona sana media de la población. Para hacer los cálculos se consideran cuatro variables que están interrelacionadas: $a$ ) actividad física; $b$ ) estructura y medida del cuerpo; $c$ ) edad, y $d$ ) clima y otros factores ecológicos.

FueNTE: United Nations, Statistical Yearbook 1990-91 (Nueva York: United Nations, 1993), pp. 179-187.

entre las calorías por persona y año que se consumen en los países de la Europa mediterránea y las que se consumen en los países africanos y asiáticos. En Libia, Turquía o Egipto se consume diariamente de media un volumen mayor de calorías por persona que en países ubicados en la Europa mediterránea 
como Portugal, Malta o Albania. A lo largo de las dos últimas décadas del siglo $\mathrm{XX}$ el número de calorías consumidas por persona y día incrementa en todos los países del Mediterráneo, excepto en Albania. Durante ese período, tanto en los países de la orilla norte como en los de las orillas sur y este, se llega a una cifra de consumo diario de más de tres mil calorías. Esta cantidad cubre las calorías necesarias requeridas por una persona en cualquiera de los países de la cuenca mediterránea (según la FAO) ${ }^{19}$. La media del porcentaje de calorías que una persona consume respecto al volumen de energía necesario es un poco superior en los países del área norte que en los del área sur. En la Europa mediterránea, en todos los países a excepción de Albania, se consume al menos una cuarta parte más de calorías de las que son requeridas por persona y día para realizar su trabajo y vivir con comodidad. Entre los países del sur y el este, tan sólo Turquía y Libia llegan a superar esta proporción de una cuarta parte de consumo excedente. La calidad de la comida parece ser mejor en el norte que en el sur. El consumo diario de proteínas, que es un indicador de la cantidad de carne y pescado que se consume, es algo superior en los países europeos del Mediterráneo que en los africanos y asiáticos.

La energía es otro bien de consumo básico relacionado con calidad de vida. La energía, independientemente del tipo que sea: gas, sólida o líquida, se puede calcular de manera homogénea en una unidad estándar: kilos de carbón por persona y año. Los datos de consumo de energía se refieren a "consumo aparente» de energía, y derivan de la fórmula: "producción + importaciones - exportaciones - almacenaje +/- variación en los stocks». En muchos casos no indican realmente consumo energético, sino la cantidad de energía disponible en el país. Este hecho es importante en el caso de Argelia y, sobre todo, en el de Libia, que son los dos grandes productores de petróleo de la cuenca mediterránea. En la tabla 9 se indica el consumo de energía per capita en 1980 y 1992. En Libia, en 1994 se consumen 3.311 kilos de carbón por persona y año. Esta cifra es superior a la de España o Grecia. Realmente, en Libia no se consume tanta energía. En la década de los ochenta y principios de los noventa el gobierno libio incrementa las reservas de petróleo como estrategia para mantener elevado el precio del crudo. Debido a la cuestión del almacenaje de energía, las cifras de consumo aparente de energía en esos dos países posiblemente están sobrevaloradas (véase el mapa 1). El dato del "consumo aparente» de energía en el resto de países de la cuenca es una aproximación del consumo energético real.

En la década de los noventa, en los países del norte de la cuenca se consume cuatro veces más energía que en los del sur. Es importante distinguir entre energía

19 Es la Organización para la Agricultura y la Alimentación. En inglés es Food and Agriculture Organization, con sede en Roma. La FAO define el porcentaje de calorías que una persona consume de media en un país respecto al volumen de energía que se considera adecuado para cubrir las necesidades energéticas de una persona media sana de la población. Para realizar los cálculos se consideran variables que están interrelacionadas: actividad física, estructura y medida del cuerpo, edad, clima y otros factores ecológicos. 


\section{TABLA 9}

Consumo de energía per capita en 1980 y 1992

Consumo de energía per capita (equivalente a kilos de carbón por año)

\begin{tabular}{|c|c|c|c|}
\hline \multirow[b]{2}{*}{ Paises de la cuenca mediterránea } & \\
\hline & 1980 & 1992 & $\begin{array}{c}\text { Porcentaje de } \\
\text { incremento }\end{array}$ \\
\hline \multicolumn{4}{|l|}{ Norte } \\
\hline 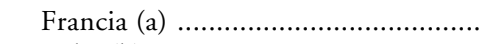 & 4.774 & 5.611 & 18 \\
\hline 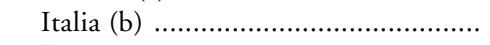 & 3.410 & 4.067 & 19 \\
\hline 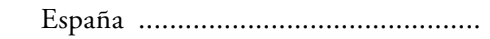 & 2.335 & 3.081 & 32 \\
\hline 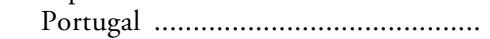 & 1.281 & 2.115 & 65 \\
\hline 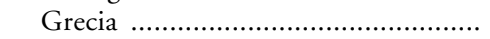 & 2.098 & 3.193 & 52 \\
\hline 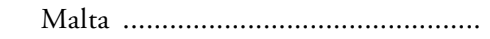 & 1.429 & 1.997 & 40 \\
\hline Albania & 1.270 & 498 & -155 \\
\hline \multicolumn{4}{|l|}{ Sur } \\
\hline 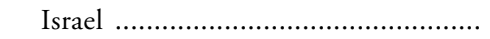 & 2.276 & 3.267 & 44 \\
\hline 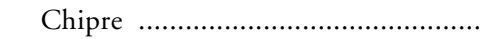 & 1.922 & 2.877 & 50 \\
\hline 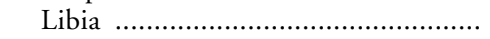 & 2.400 & 3.311 & 38 \\
\hline 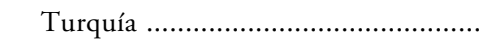 & 699 & 1.035 & 48 \\
\hline Siria & 992 & 1.298 & 31 \\
\hline 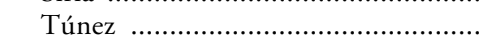 & 643 & 793 & 22 \\
\hline 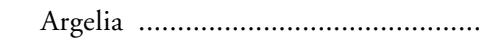 & 1.322 & 1.426 & 8 \\
\hline 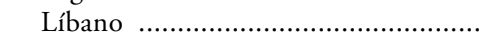 & 951 & 1.870 & 97 \\
\hline 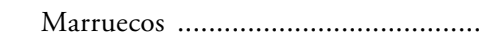 & 336 & 402 & 20 \\
\hline 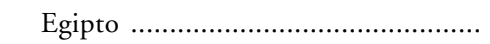 & 478 & 656 & 36 \\
\hline
\end{tabular}

Notas: Los datos de consumo de energía se refieren a "consumo aparente» de energía, y derivan de la fórmula: "producción + importaciones - exportaciones - almacenaje +/- variación en los stocks". A menudo no son datos de consumo, sino de la cantidad de energía disponible en el país.

(a) Incluye Mónaco.

(b) Incluye San Marino.

Fuente: United Nations, Statistical Yearbook 1993-94 (Nueva York: United Nations, 1995), pp. 574-599.

que se destina a producción económica y energía que se destina a uso doméstico. Un aumento de la energía que se destina a uso doméstico repercute de manera directa en la calidad de vida de las personas, y a lo largo de la década de los noventa el volumen de energía que se destina a los hogares es similar en las dos orillas. La diferencia norte/sur de cuatro a uno deriva del volumen de energía mayor que los países europeos de la cuenca utilizan en actividades industriales. El consumo de energía correlaciona de manera alta con el producto interior bruto per capita de los países mediterráneos porque la fórmula que se utiliza para calcular el «consumo aparente de energía» tiene en cuenta tan sólo variables económi- 


\section{MAPA 1}

Consumo de energía per capita

(Equivalente a kilos de carbón por año)

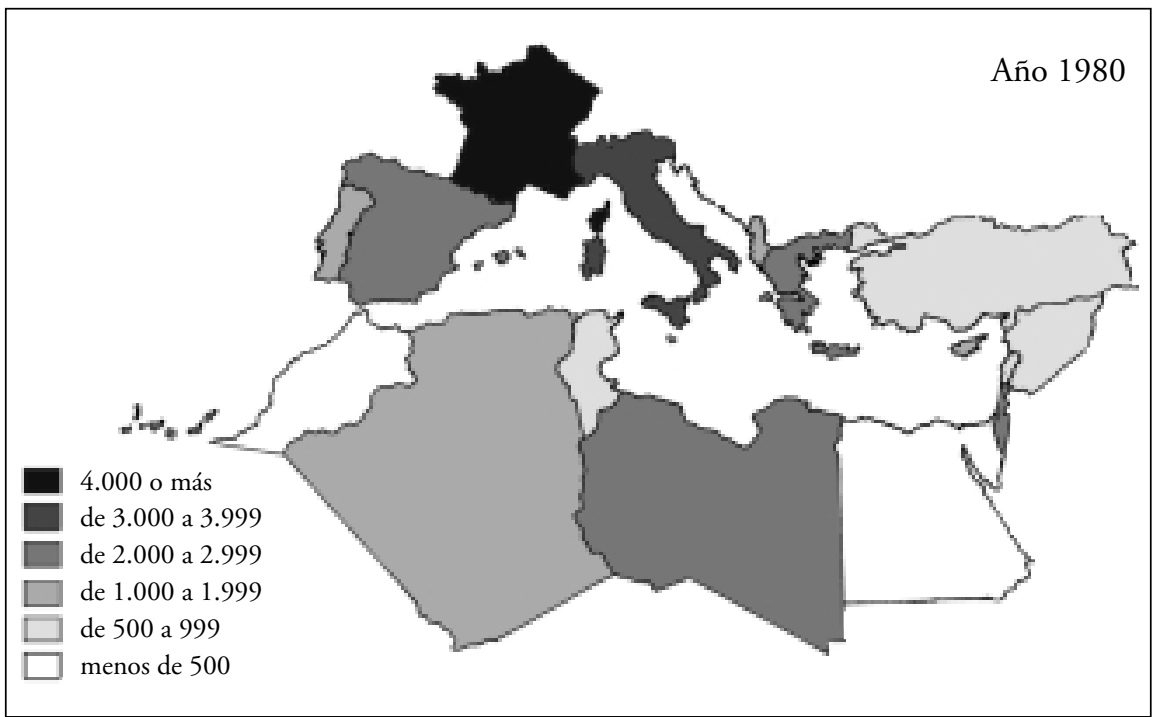

Fuente: Tabla 9.

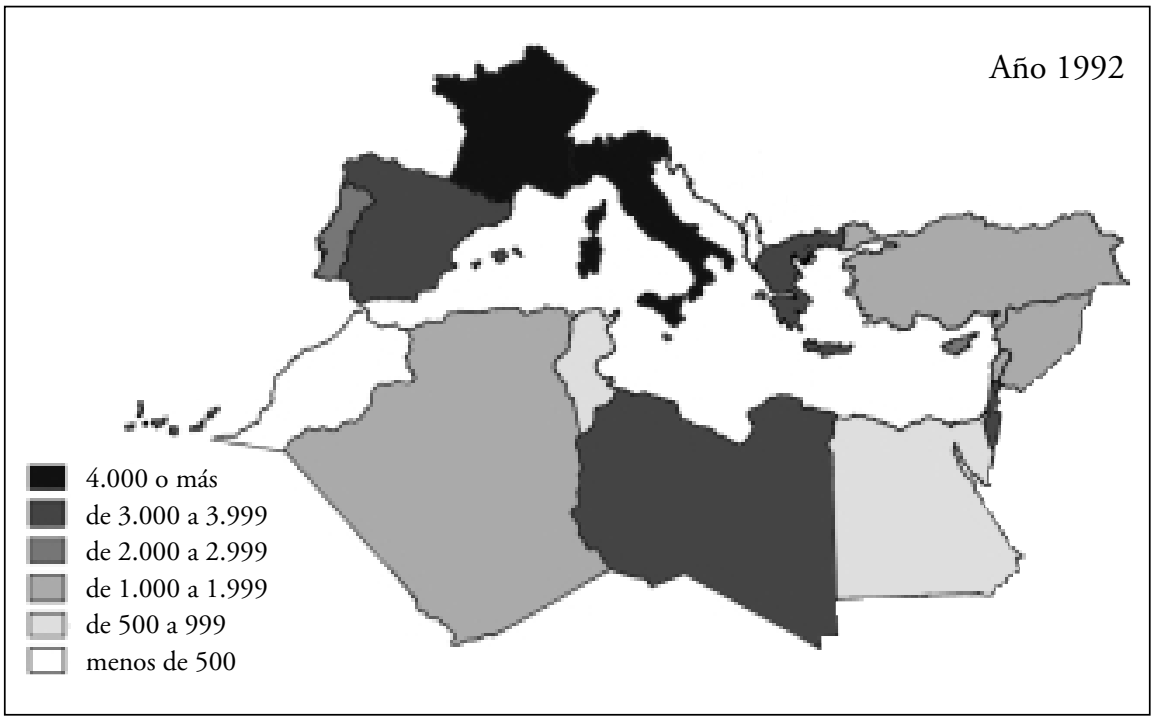

Fuente: Tabla 9. 
cas. Los incrementos mayores en el consumo de energía a lo largo de la década de los ochenta y la de los noventa corresponden a Portugal y Grecia, que son los dos países de la orilla norte que sufren un desarrollo industrial más importante durante el período. Es un indicador de que en Europa el incremento del consumo energético es más industrial que familiar. En 1980 los países europeos tienen ya un consumo doméstico de energía alto. En los países africanos y asiáticos el aumento más significativo en el consumo de energía se produce en el momento en que el sector industrial pierde importancia. Este incremento es debido a un consumo mayor de energía en los hogares y no en la producción industrial.

Los países del sur y este de la cuenca mediterránea tienen cubiertas las necesidades básicas de consumo. En este aspecto no existen diferencias importantes entre las dos orillas. Sí que existen desigualdades en ciertos bienes de consumo. La proporción de coches por habitante en el norte es diez veces mayor que en el sur, y la de teléfonos y aparatos de fax siete veces mayor. Los países del norte de la cuenca tienen una proporción media de unos cuatro teléfonos por cada diez habitantes, casi un teléfono por cada dos personas. En los países del sur y el este de la cuenca la proporción es bastante menor. Israel, Chipre y Túnez son los únicos países meridionales del Mediterráneo que tienen una proporción de teléfonos indicativa de que es un bien de uso doméstico bien distribuido, es decir, que se encuentra con frecuencia en los hogares.

El desarrollo industrial en un país tiene una relación alta con incrementos en el volumen del parque móvil. El aumento de la tasa de "turismos» (es decir, automóviles particulares) por 1.000 habitantes, pero sobre todo el del número de vehículos comerciales, es un indicador de desarrollo industrial, tanto si se tiene en cuenta desde el punto de vista de la oferta como de la demanda. En la tabla 10 se observa que el incremento de automóviles y el de vehículos comerciales entre 1980 y 1993 es elevado en España, Portugal y en Grecia, que son países con un desarrollo industrial importante a lo largo de la década de los ochenta. En los países del sur y el este de la cuenca el aumento del volumen del parque móvil, tanto por lo que respecta a turismos como a vehículos comerciales, es menor que en los del norte. El movimiento de mercancías por vía férrea no cambia mucho en los países de la Europa mediterránea. En los del sur se incrementa a lo largo de la década, aunque no de manera exagerada. Si se hace la suposición de que el sistema de transporte principal para los productos industriales, en el caso de los países del sur y el este de la cuenca mediterránea, es el ferrocarril y no el transporte rodado por carretera, los incrementos en el volumen de mercancías a lo largo de la década no son suficientemente importantes para que indiquen un desarrollo industrial importante.

A lo largo de la década de los ochenta y la de los noventa, en el sur aumenta el consumo de ciertos productos relacionados con cultura, comunicaciones e información que son indicadores de modernidad, dinamismo y cambio social. La diferencia en el consumo de periódicos, que es un bien barato vinculado a la cultura, no es tan grande entre sur y norte como en otro tipo de 


\section{TABLA 10}

\section{Transporte}

\begin{tabular}{|c|c|c|c|c|c|c|c|c|}
\hline \multirow{3}{*}{$\begin{array}{c}\text { Paises de la cuenca } \\
\text { mediterránea }\end{array}$} & \multicolumn{4}{|c|}{$\operatorname{Tren}(\mathrm{a})$} & \multicolumn{4}{|c|}{ Automóviles en circulación } \\
\hline & \multicolumn{2}{|c|}{$\begin{array}{l}\text { Pasajeros por Km } \\
\quad \text { (millones) (b) }\end{array}$} & \multicolumn{2}{|c|}{$\begin{array}{l}\text { Toneladas } \\
\text { por Km (c) }\end{array}$} & \multicolumn{2}{|c|}{$\begin{array}{c}\text { Turismos } \\
\text { (por mil } \\
\text { habitantes) (d) }\end{array}$} & \multicolumn{2}{|c|}{$\begin{array}{c}\text { Vehiculos } \\
\text { comerciales } \\
\text { (por mil } \\
\text { habitantes) (e) }\end{array}$} \\
\hline & 1980 & 1993 & 1980 & 1993 & 1980 & 1993 & 1980 & 1993 \\
\hline \multicolumn{9}{|l|}{ Norte } \\
\hline Francia ................ & 54.496 & 58.430 & 68.815 & 45.900 & 341 & 425 & 50 & 70 \\
\hline Italia $\ldots \ldots \ldots \ldots \ldots \ldots$ & 39.587 & 17.870 & 18.384 & 21.830 & 314 & 517 & 30 & $48(f)$ \\
\hline España .................. & 13.527 & 12.077 & 10.278 & 9.360 & 202 & 344 & 37 & 73 \\
\hline Portugal .............. & 6.077 & 1.239 & 1.001 & 1.784 & 128 & 333 & 47 & 106 \\
\hline Grecia ................... & 1.464 & 1.726 & 814 & 523 & 89 & 190 & 42 & 82 \\
\hline Malta ................... & $\ldots$ & $\ldots$ & $\ldots$ & $\ldots$ & 183 & 424 & 40 & 141 \\
\hline Croacia.................. & $\ldots$ & 1.056 & $\ldots$ & 1.680 & $\ldots$ & $\ldots$ & $\ldots$ & $\ldots$ \\
\hline Albania ................ & $\ldots$ & 779 & $\ldots$ & 584 & $\ldots$ & $\ldots$ & $\ldots$ & $1(\mathrm{~g})$ \\
\hline \multicolumn{9}{|l|}{ Sur } \\
\hline Israel ..................... & 252 & 970 & 819 & 1.092 & 105 & 179 & 23 & 38 \\
\hline Chipre ................. & $\ldots$ & $\ldots$ & $\ldots$ & $\ldots$ & 154 & 290 & 42 & 132 \\
\hline Libia ..................... & $\ldots$ & $\ldots$ & $\ldots$ & $\ldots$ & 142 & $91(\mathrm{f})$ & 70 & $66(f)$ \\
\hline Turquía ................ & 6.012 & 7.679 & 5.028 & 8.517 & 17 & 44 & 7 & 9 \\
\hline 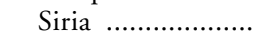 & 382 & 966 & 579 & 1.077 & 8 & 11 & 10 & 12 \\
\hline Túnez ................... & 862 & 1.695 & 1.698 & 2.016 & 20 & 37 & 18 & 21 \\
\hline Argelia ................... & 2.070 & 3.192 & 2.461 & 2.710 & 26 & $28(f)$ & 14 & $18(\mathrm{f})$ \\
\hline Marruecos ............ & 936 & 4.517 & 3.834 & 4.415 & 22 & 32 & 10 & 12 \\
\hline Egipto ................... & 10.699 & 36.644 & 2.174 & 3.229 & 10 & 20 & 3 & 8 \\
\hline
\end{tabular}

NotAs: (a) Los datos son para tráfico doméstico e internacional en todas las líneas férreas dentro de cada país, excepto las que corresponden a trenes interurbanos, funiculares, tranvías o trenes mineros.

(b) Pasajeros por $\mathrm{Km}$ incluye toda persona que toma el tren pagando el abono; es decir, que los empleados de la compañía ferroviaria no están incluidos.

(c) Se incluye servicio ordinario y rápido de mercancías. Se excluye el correo, los equipajes de los pasajeros, así como stocks gubernamentales que no pagan billete.

(d) En turismos se incluyen los vehículos con capacidad para un máximo de nueve personas (incluyendo al conductor). No se incluyen vehículos de dos o tres ruedas.

(e) Vehiculos comerciales son furgonetas, camiones y autobuses. Se excluyen los trailers y los tractores.

(f) Datos para 1992.

(g) Datos para 1990.

Fuente: United Nations, Statistical Yearbook 1993-94 (Nueva York: United Nations, 1995), pp. 507-531. 
productos. El nivel de difusión de periódicos diarios es un indicador de lo dinámica y moderna que es la sociedad de un país. Está relacionado con la cultura de la población y sirve para determinar el volumen de información que llega al alcance de los/as ciudadanos. En la tabla 11 se muestra la evolución del consumo de diferentes medios de comunicación en las dos últimas décadas del siglo XX. En 1995, en los países del norte de la cuenca mediterránea se consumen más del doble de periódicos que en los del sur y este. En la Europa mediterránea se consume diariamente de media un periódico por cada 10 habitantes; y en los países africanos y asiáticos de la cuenca, uno por cada 20. La proporción de periódicos consumidos por las personas de un país correlaciona, aunque no de manera excesiva, con el desarrollo económico del mismo. En la Europa mediterránea, el país que presenta una tasa más alta de periódicos por habitante es Croacia, donde se distribuyen casi seis periódicos por cada diez personas. Francia ocupa el segundo lugar del ranking, con una proporción de 2,5 periódicos por cada diez habitantes. El país de la Europa mediterránea donde diariamente se consumen menos periódicos por habitante es Portugal, que tiene un consumo de menos de un periódico diario por cada veinte personas. Sin embargo, Portugal es ya el cuarto país más desarrollado del Mediterráneo europeo.

La diversidad en la distribución de periódicos diarios por habitante entre los países del sur y el este de la cuenca mediterránea es mayor que entre los países del norte. En 1995, los/as israelitas consumen diariamente casi tres periódicos por cada diez personas; en cambio, en Libia o en Marruecos se consume poco más de un periódico diario por cada cien habitantes. En los países asiáticos y africanos del Mediterráneo, la relación entre tasa de consumo de periódicos diarios y nivel de desarrollo económico es aún más ambigua que en los países europeos de la cuenca. Un país como Líbano, que a la mitad de la década de los noventa posee el cuarto PIB per capita más bajo de toda la cuenca mediterránea, tiene una tasa de distribución de periódicos por cada mil habitantes de 172 , superior a la de cualquier otro país del sur y el este de la cuenca (excepto Israel) y de la mayoría de los del norte. Se venden 70 periódicos más por cada mil habitantes en el Líbano que en Italia o España, que tienen un PIB per capita 20 y 14 veces superior. El Líbano es un país que durante varias décadas muestra una evolución económica y social parecida a la de Israel, pero se estanca en los años setenta. Aunque económicamente el país pierde importancia, la población tiene más estudios superiores que la de la mayoría de países asiáticos y africanos del Mediterráneo, y la organización social y sanitaria no se destruye y sigue siendo eficiente. La calidad de vida de las personas es más alta que en otros países más ricos del área. Es una demostración de que cuando las variables de calidad de vida evolucionan positivamente en un país, por las circunstancias que sean, aunque el país padezca posteriormente una recesión económica fuerte, el nivel de calidad de vida acostumbra a mantenerse. Lo que se gana en este sentido no acostumbra ya a perderse.

En los países africanos y asiáticos del Mediterráneo la relación del factor cultural con el consumo diario de periódicos aparece de manera clara. A dife- 
TABLA 11

Consumo de medios de comunicación en 1980 y en 1994

\begin{tabular}{|c|c|c|c|c|c|c|c|c|c|c|}
\hline \multirow[b]{4}{*}{ Paises de la cuenca mediterránea } & \multicolumn{6}{|c|}{ Periódicos (a) } & \multirow{2}{*}{\multicolumn{2}{|c|}{ Radio }} & \multirow{2}{*}{\multicolumn{2}{|c|}{ Televisión }} \\
\hline & \multirow{2}{*}{\multicolumn{2}{|c|}{$\begin{array}{l}\text { Periódicos } \\
\text { diferentes }\end{array}$}} & \multicolumn{4}{|c|}{ Difusión diaria media } & & & & \\
\hline & & & & al & $\begin{array}{r}\text { Tasa } \\
\text { hab }\end{array}$ & $\begin{array}{l}\text { mil } \\
\text { tes }\end{array}$ & \multicolumn{2}{|c|}{$\begin{array}{l}\text { Recibidores por } \\
\text { cien habitantes }\end{array}$} & \multicolumn{2}{|c|}{$\begin{array}{l}\text { Recibidores por } \\
\text { cien habitantes }\end{array}$} \\
\hline & 1980 & 1984 & 1980 & 1994 & 1980 & 1995 & 1980 & 1994 & 1980 & 1994 \\
\hline \multicolumn{11}{|l|}{ Norte } \\
\hline 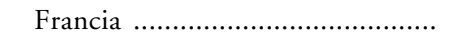 & 90 & 118 & 10.332 & 13.685 & 192 & 237 & 74 & 89 & 35 & 59 \\
\hline 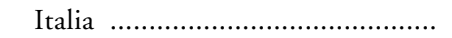 & 82 & 74 & 4.775 & 5.985 & 85 & 105 & 60 & 80 & 39 & 44 \\
\hline España ..................................... & 111 & 148 & 3.487 & 4.100 & 93 & 104 & 26 & 31 & 25 & 40 \\
\hline 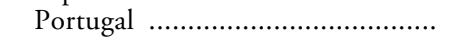 & 28 & 23 & 480 & 404 & 49 & 41 & 17 & 23 & 16 & 32 \\
\hline Eslovenia .................................. & 3 & 6 & 198 & 360 & 108 & 185 & 27 & 38 & 25 & 32 \\
\hline Grecia ................................... & 128 & 168 & 1.160 & 1.622 & 120 & 156 & 34 & 42 & 17 & 21 \\
\hline 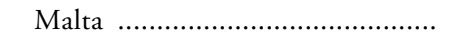 & 5 & 3 & 60 & 64 & 185 & 176 & 51 & 53 & 62 & 75 \\
\hline Croacia .................................. & $\ldots$ & 6 & $\ldots$ & 2.600 & $\ldots$ & 573 & 24 & 26 & 22 & 25 \\
\hline Serbia-Montenegro ..................... & 12 & 9 & 537 & 966 & 56 & 90 & $\ldots$ & $\ldots$ & 17 & 18 \\
\hline Bosnia-Herzegovina ................... & $\ldots$ & 2 & $\ldots$ & 518 & $\ldots$ & 131 & $\ldots$ & 23 & $\ldots$ & $\ldots$ \\
\hline Albania ......................................... & 2 & 3 & 145 & 185 & 54 & 54 & 15 & 19 & 4 & 9 \\
\hline \multicolumn{11}{|l|}{ Sur } \\
\hline Israel ........................................... & 36 & 34 & 1.000 & 1.534 & 258 & 281 & 25 & 48 & 23 & 28 \\
\hline 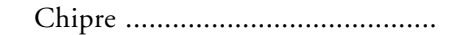 & 12 & 15 & 80 & 81 & 127 & 110 & 26 & 30 & 14 & 32 \\
\hline 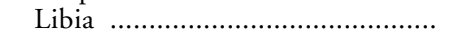 & 3 & 4 & 55 & 70 & 18 & 13 & 7 & 23 & 6 & 10 \\
\hline Turquía ...................................... & $\ldots$ & 57 & 2.500 & 2.679 & 56 & 44 & 16 & 20 & 8 & 18 \\
\hline 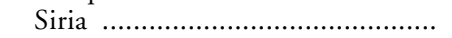 & 7 & 8 & 194 & 261 & 13 & 18 & 20 & 26 & 4 & 6 \\
\hline Túnez ...................................... & 5 & 7 & 272 & 403 & 43 & 46 & 11 & 16 & 5 & 8 \\
\hline Argelia ........................................ & 4 & 6 & 448 & 1.250 & 24 & 46 & 20 & 24 & 5 & 8 \\
\hline Líbano ...................................... & 14 & 16 & 290 & 500 & 109 & 172 & 75 & 89 & 28 & 36 \\
\hline Marruecos ............................... & 11 & 13 & 270 & 344 & 14 & 13 & 16 & 22 & 5 & 8 \\
\hline Egipto ....................................... & 12 & 17 & 1.701 & 3.949 & 39 & 64 & 14 & 31 & 3 & 11 \\
\hline
\end{tabular}

(a) Se considera periódico a toda publicación impresa en el país y ofrecida al público, exceptuando publicaciones publicitarias, de carácter efímero, o cuyo contenido principal no sea texto.

FUENTES: United Nations, Statistical Yearbook 1993-94 (Nueva York: United Nations, 1995), pp. 109-115 y 124-131; UNESCO, Statistical Yearbook 1996 (Nueva York: United Nations, 1997), pp. 7-89 a 7-92 y 9-1 a 9-15. 
rencia de lo que sucede en la Europa mediterránea, donde el determinante para que el consumo de prensa diaria sea alto es la proporción de población que tiene estudios secundarios o superiores, en los países del sur y este de la cuenca es más importante el porcentaje de personas que tienen algún nivel de escolarización, aunque sea tan sólo primario. Lo importante es medir la proporción de personas que pueden leer y entender lo que leen. El Líbano y Turquía, que son países que comparativamente con el resto de los del área tienen un volumen alto de personas con estudios, presentan un consumo de periódicos alto, incluso superior al de Portugal. El Líbano, que descontando a Israel y Chipre es el país del bloque sur con una población más educada, tiene un consumo de periódicos tan sólo un poco más bajo que el de Francia. Marruecos, que es el país con un porcentaje más alto de personas analfabetas, es además el que tiene las tasas de distribución de periódicos más bajas de todo el Mediterráneo.

Túnez, Argelia y sobre todo Egipto, que son países con tasas altas de analfabetismo, tienen, sin embargo, una tasa de distribución de periódicos por cada mil habitantes que es incluso superior a la de Portugal (véase el mapa 2). Es una muestra más de la estructura social dual frecuente en los países del norte de África. Las clases media y alta urbanas tienen educación y consumen abundante información y cultura escrita. Las clases bajas y rurales no pueden hacerlo. Existe una diferencia de clase social que no es sólo económica, sino también cultural. Esa estructura se muestra de manera clara en Egipto. Es previsible que esta distribución de clases sociales de tipo dual cambie en un futuro debido a que la escolarización en todos los países, africanos y asiáticos, de la cuenca es prácticamente universal al nivel de primaria; y en el nivel de secundaria se empiezan a alcanzar las tasas de escolarización de los países mediterráneos europeos.

Túnez, Argelia o Egipto, que tienen tasas de analfabetismo cercanas e incluso superiores a la mitad de la población, presentan una tasa de consumo de prensa diaria que es la mitad de la italiana o española. Si se tiene en cuenta que el porcentaje de compradores potenciales de periódicos en Túnez o en Egipto también es la mitad que en España o en Italia, que son países con tasas de analfabetismo bajas, las tasas de consumo de periódicos entre esos cuatro países son parecidas. Si se descuenta la proporción de población analfabeta del volumen de proporción total en los países del sur y este de la cuenca, las tasas de consumo de prensa diaria no difieren mucho de las de los países de la Europa mediterránea. Además, en las próximas décadas, gracias a la universalización de la educación general básica en los países del sur y el este de la cuenca, el número de personas analfabetas se va a reducir. Por lo tanto, es probable que la proporción de consumo de prensa diaria por parte del global de la población en los países del bloque sur se iguale con la de los del bloque norte.

Es posible que sea más importante y generalizada la información que se recibe de la radio y la televisión que la que proviene de los periódicos. Ade- 


\section{MAPA 2}

Consumo diario de periódicos

(Ejemplares por mil habitantes)

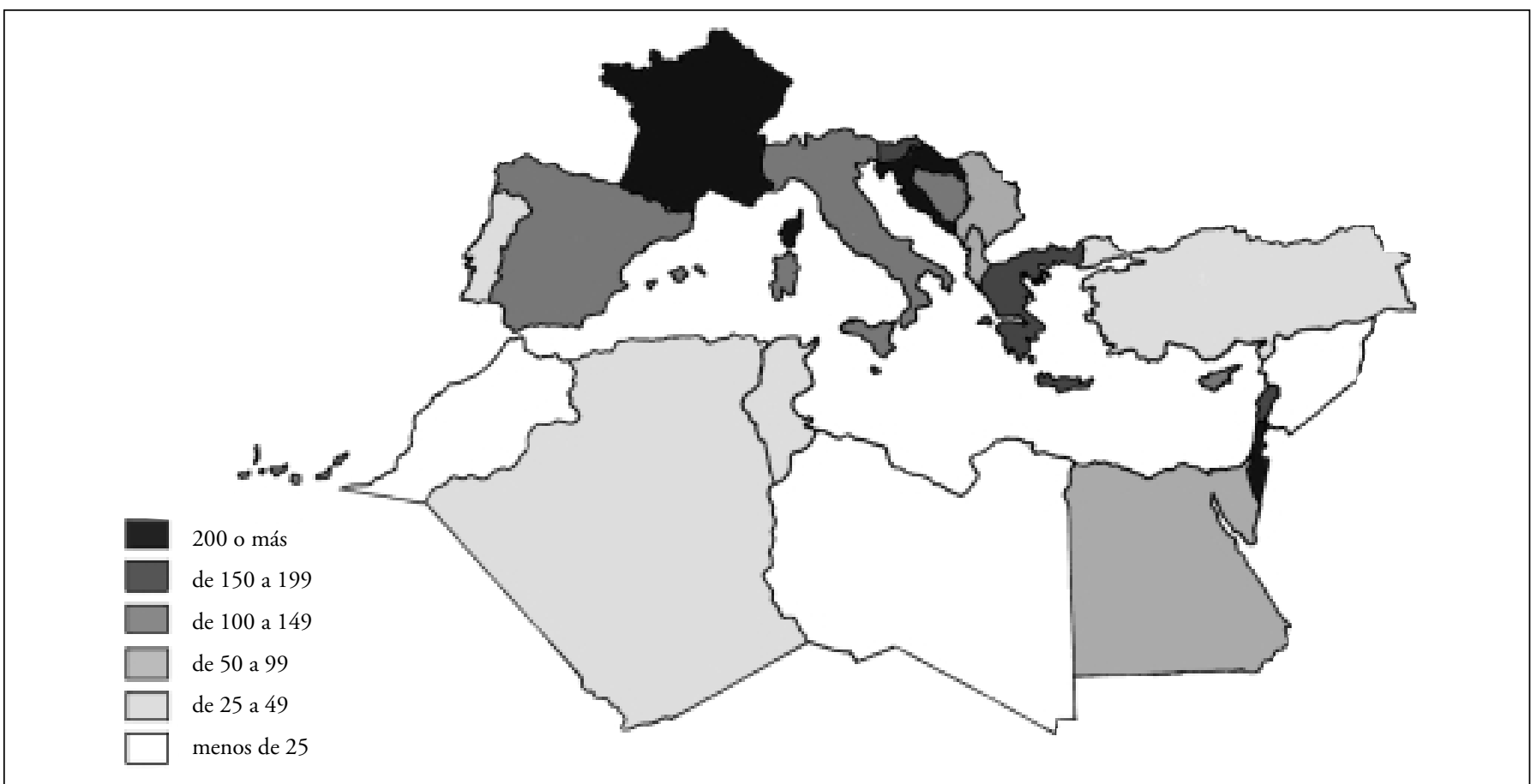


más, ese tipo de información es más equitativa entre diversos niveles culturales. Las personas analfabetas, o con niveles bajos de educación, tienen la posibilidad de entender la información vista y oída. Es una información que puede llegar de manera más igualitaria al conjunto de población de todos los países de la cuenca mediterránea independientemente de las diferencias en las tasas de analfabetismo. En todos los países mediterráneos se consume más radio y televisión que prensa. En 1994, en los países europeos de la cuenca existe un promedio de 69 radios por cada cien habitantes. En Francia, la proporción es de casi una radio por persona. En los países del sur, el promedio es de una radio por cada cuatro personas. La tasa de televisores por habitantes es algo menor tanto en los países europeos como en los africanos y asiáticos. En los países del norte de la cuenca se dispone de una media de 43 televisores por cada cien personas. La proporción es de casi un televisor por cada dos personas. En los países del sur y este de la cuenca mediterránea la proporción es de 13 televisores por cada cien personas; es decir, un televisor por cada siete u ocho personas.

Tanto la radio como la televisión son bienes sociales de consumo familiar. A pesar de que en el norte el tamaño de la unidad familiar es menor que en el sur, el número alto de televisores por habitante indica que hay más de un televisor por hogar de promedio. En los países africanos y asiáticos de la cuenca, las mujeres tienen más hijos y la unidad familiar es más numerosa. En 1994, no es arriesgado aventurar que con una proporción media de una radio por cada cuatro personas y una televisión por cada siete u ocho, casi cada hogar debe disponer al menos de un aparato de radio y un televisor. En 1994, la información que proviene de la radio y la televisión llega de manera parecida a la gran mayoría de hogares mediterráneos, tanto del norte como del sur. En los países europeos del Mediterráneo la capacidad de consumo más elevada de las personas hace que exista más de un televisor y una radio en los hogares. Aunque por tener más receptores en casa no llega un volumen mayor de información. La función de un solo televisor o una radio en una casa es prácticamente la misma que la de tres. Es una de las paradojas de la sociedad de consumo. Que exista uno o más receptores de televisión y radio en un hogar es sociológicamente poco importante.

En los países africanos y asiáticos del Mediterráneo, la proporción de un aparato de televisión en cada hogar se alcanza recientemente. En 1980 existe una media de seis receptores de televisión por cada cien habitantes en los países del sur y este del Mediterráneo. La radio, que es un medio de comunicación más tradicional, en ese momento está más extendida que el televisor. Durante los quince años estudiados, en los países europeos del Mediterráneo se incrementa el número de radios y de televisores en los hogares de manera ostensible. Pero en los países africanos y asiáticos el progreso es más importante sociológicamente. Si bien en 1980 la radio ya está extendida en la mayoría de hogares africanos y asiáticos de la cuenca, en 1994 también la televisión puede ser vista en el seno familiar. Ese hecho conlleva universalización en el 
consumo de un tipo de comunicación que es importante, primero, por el volumen de información que aporta $y$, segundo, por su capacidad de romper fronteras culturales. Lo más importante es que la información vista y oída es universal, posible de entender para todas las personas, sepan o no leer y escribir. Ése es un elemento clave en los países del sur y el este de la cuenca del Mediterráneo, que tienen índices de analfabetismo que llegan al 50 por 100 . Se puede afirmar que, en parte, la mejora de la calidad de vida en los países africanos y asiáticos de la cuenca a lo largo de estos quince años se debe a una expansión mayor de los mass media.

Después de obtener la independencia, la mayoría de los países musulmanes del Mediterráneo siguen la doctrina reformadora del Islam moderno. Los sectores urbanos privilegiados, como la burguesía industrial, o las élites políticas se emancipan parcialmente de la doctrina estricta del Islam esgrimiendo ideologías nacionalistas que se reflejan en una estructura económica-industrial de tipo socialista. La mentalidad nacionalista y socialista conlleva el desarrollo de un sistema de bienestar en muchos de esos países que aporta mejoras significativas a la calidad de vida de las personas. Fruto de esa mentalidad es la creación reciente de una estructura educativa universal y de calidad. El sector de la educación es, posiblemente, el más significativo para mostrar y explicar el desarrollo invisible que se produce en las orillas sur y este de la cuenca mediterránea. El porcentaje medio del PIB que los países del bloque sur del Mediterráneo destinan a financiar el sector de la educación es mayor que el que destinan los del norte (véase el mapa 3). Los países de la Europa mediterránea gastan de media un 4 por 100 del PIB en la enseñanza. Las cifras fluctúan entre un gasto del 5 por 100 del PIB en Francia, que es el país del norte de la cuenca que realiza un esfuerzo económico mayor en el sector de la educación, hasta 2,2 y 2,6 por 100 en Grecia y España, respectivamente. Los países del sur y este de la cuenca mediterránea gastan de media un 5 por 100 del PIB en educación; es decir, un 1 por 100 más que los del norte.

Los países africanos y asiáticos del Mediterráneo poseen tasas de escolarización de alumnos/as de primaria que son casi universales ${ }^{20}$. La tabla 12 muestra las tasas de escolarización brutas y netas por cada nivel de educación en el año 1994. El único país que presenta problemas de escolarización en el caso de los/as niños más pequeños es Marruecos, que tiene una tasa bruta de escolari-

${ }^{20}$ La tasa de escolarización bruta es la relación entre el total de las matrículas escolares, independientemente de la edad de los alumnos/as, y la población del grupo de edad correspondiente a ese grado. La tasa de escolarización neta se calcula tomando en consideración sólo aquella parte de la matrícula cuya edad corresponde al grado de enseñanza dado que se considera. Para calcular la tasa de escolarización neta es necesario tener datos de la matrícula por edad. En muchos casos, la tasa bruta de escolarización es de más del cien por cien porque hay alumnos/as que estudian un grado de enseñanza a una edad que no es la correspondiente a la considerada usual en ese nivel. En el caso de la tasa neta de escolarización el máximo es del cien por cien. La tasa bruta de escolarización es igual de eficiente que la neta para indicar el volumen, las tendencias y los cambios que se producen en el nivel de personas escolarizadas a lo largo del tiempo. 
MAPA 3

Porporción del PIB dedicado a educación en 1994

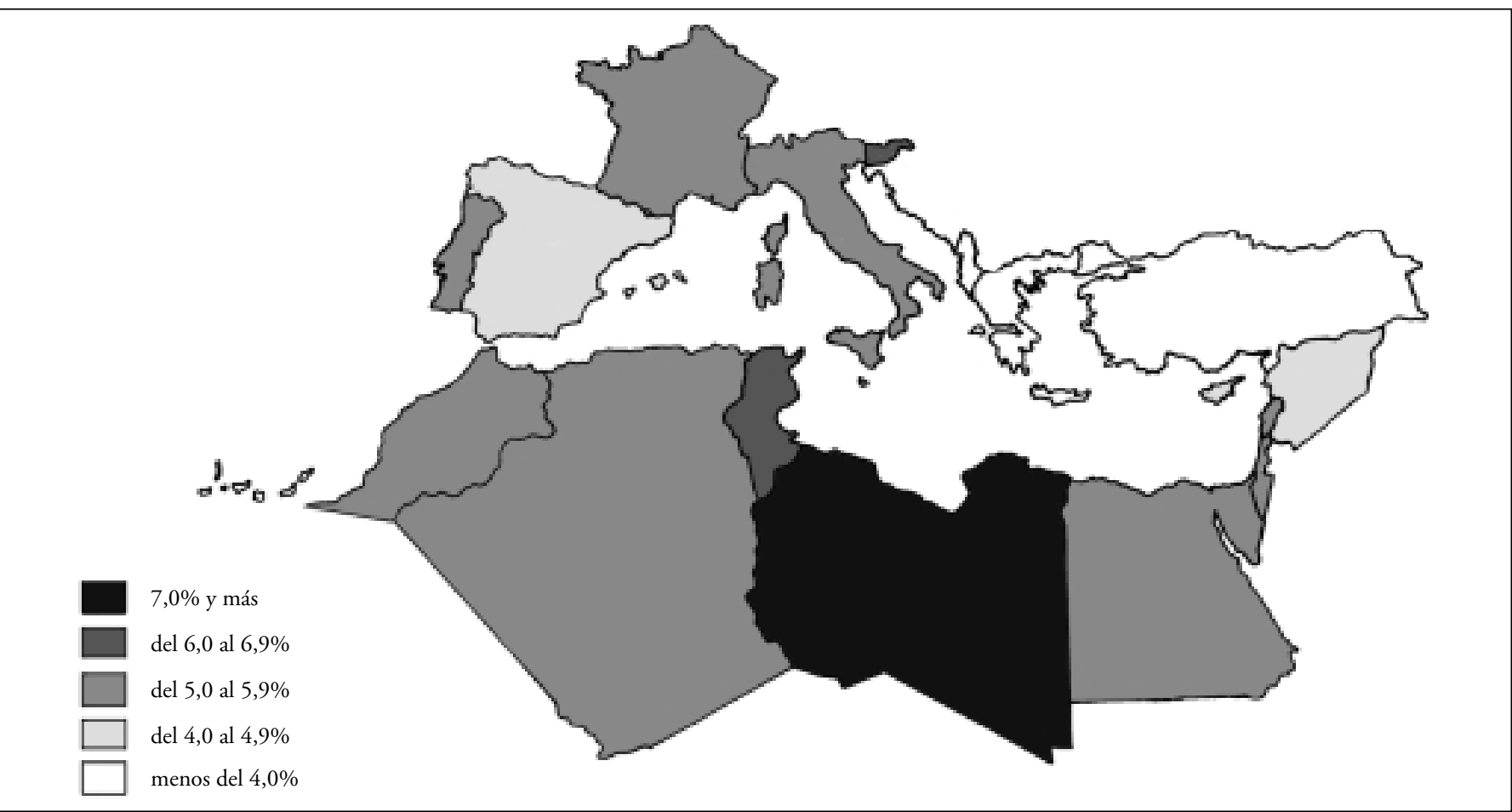

Fuente: Tabla 10. 
TABLA 12

Tasa de escolarización según el nivel de enseñanza en 1994

(En porcentajes)

\begin{tabular}{|c|c|c|c|c|c|c|c|c|c|c|c|c|}
\hline \multirow[b]{3}{*}{ Países de la cuenca mediterránea } & \multicolumn{4}{|c|}{ Primaria } & \multicolumn{4}{|c|}{ Secundaria } & \multirow{2}{*}{\multicolumn{4}{|c|}{$\begin{array}{cc}\text { Primaria }+ \text { Secundaria } & \text { Tercer grado } \\
\text { Bruta } & \text { Bruta }\end{array}$}} \\
\hline & \multicolumn{2}{|c|}{ Tasa bruta } & \multicolumn{2}{|c|}{ Tasa neta } & \multicolumn{2}{|c|}{ Bruta } & \multicolumn{2}{|c|}{ Neta } & & & & \\
\hline & Total & Mujeres & Total & Mujeres & Total & Mujeres & Total & Mujeres & Total & Mujeres & Total & Mujeres \\
\hline \multicolumn{13}{|l|}{ Norte } \\
\hline Francia (a) & 106 & 105 & 99 & 99 & 106 & 107 & 90 & 92 & 106 & 106 & 50 & 55 \\
\hline Italia (a) ................ & 98 & 99 & $\ldots$ & $\ldots$ & 81 & 82 & $\ldots$ & $\ldots$ & 87 & 87 & 37 & 39 \\
\hline 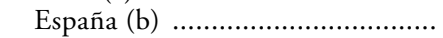 & 105 & 105 & 100 & 100 & 110 & 115 & 90 & 92 & 108 & 112 & 41 & 44 \\
\hline 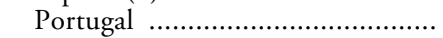 & $120(\mathrm{c})$ & $118(\mathrm{c})$ & $100(\mathrm{c})$ & $100(\mathrm{c})$ & 84 & $\ldots$ & $\ldots$ & $\ldots$ & 99 & $\ldots$ & 34 & $\ldots$ \\
\hline 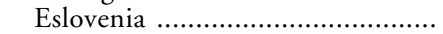 & 100 & 100 & 96 & 97 & 90 & 91 & $\ldots$ & $\ldots$ & 93 & 94 & 30 & 35 \\
\hline 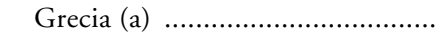 & 95 & 95 & 91 & 91 & 98 & 96 & 86 & 86 & 96 & 95 & 42 & 41 \\
\hline 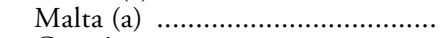 & 108 & 107 & 99 & 98 & 88 & 83 & 83 & 80 & 97 & 94 & 20 & 20 \\
\hline 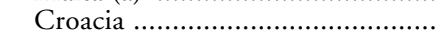 & 86 & 86 & 82 & 82 & 78 & 81 & 66 & 68 & 84 & 84 & 27 & 27 \\
\hline Albania .................................... & 98 & 99 & $\ldots$ & $\ldots$ & 36 & 37 & $\ldots$ & $\ldots$ & 79 & 79 & 10 & 11 \\
\hline
\end{tabular}

Sur

\begin{tabular}{|c|c|c|c|c|c|c|c|c|c|c|c|c|}
\hline Israel (a) ................................ & 95 & 95 & $\ldots$ & $\ldots$ & 86 & 89 & $\ldots$ & $\ldots$ & 92 & 93 & 34 & 35 \\
\hline Chipre ................................ & 100 & 100 & 96 & 96 & 97 & 98 & 92 & 93 & 99 & 99 & 17 & 19 \\
\hline 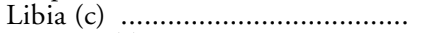 & 108 & 105 & $\ldots$ & $\ldots$ & 95 & 95 & $\ldots$ & $\ldots$ & 106 & 103 & 16 & 15 \\
\hline Turquía (a) .............................. & 97 & 94 & 90 & 87 & 64 & 50 & 56 & 46 & 80 & 71 & 20 & 15 \\
\hline 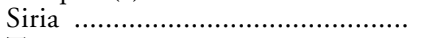 & 103 & 97 & 93 & 89 & 45 & 41 & 40 & 37 & 77 & 72 & $18(b)$ & $15(b)$ \\
\hline Túnez ........................................ & 118 & 113 & 99 & 96 & 56 & 53 & $\ldots$ & $\ldots$ & 86 & 82 & 12 & 11 \\
\hline Argelia ...................................... & 105 & 98 & 95 & 91 & 62 & 58 & 55 & 52 & 84 & 79 & $11(\mathrm{~b})$ & 8 (b) \\
\hline Líbano ...................................... & 112 & 110 & $\ldots$ & $\ldots$ & 79 & 83 & $\ldots$ & $\ldots$ & 94 & 95 & $29(\mathrm{c})$ & $28(\mathrm{c})$ \\
\hline 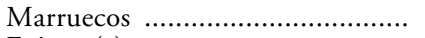 & 80 & 68 & 69 & 59 & 38 & 32 & 30 & 26 & 59 & 50 & 10 & 8 \\
\hline Egipto (a) ............................................ & 97 & 89 & 89 & 82 & 76 & 69 & 65 & 60 & 86 & 79 & 17 & 12 \\
\hline
\end{tabular}

NoTAS: Todas las tasas de escolarización se expresan en porcentaje. La tasa de escolarización bruta es la relación entre el total de la matrícula escolar, independientemente de la edad de los alumnos, y la población del grupo de edad oficial correspondiente a ese grado. La tasa de escolarización neta se calcula tomando en consideración solamente aquella parte de la matrícula cuya edad corresponde al grado de enseñanza dado considerado. Para calcular la tasa de escolarización neta es necesario disponer de la matrícula por edad.

(a) Son datos para 1993.

(b) Son datos para 1992.

(c) Son datos para 1991.

FUENTE: UNESCO, Statistical Yearbook 1996 (Nueva York: United Nations, 1997), pp. 3-17 a 3-73. 
zación en primaria del 80 por 100 y una tasa neta del 70 por 100 . El segundo país del bloque sur que presenta una tasa neta de escolarización más baja es Egipto, con 90 por 100 de niños/as en edad de estar en primaria escolarizados. Esta tasa es superior a la de Croacia $(82$ por 100$)$ y prácticamente igual a la de Grecia (91 por 100), que son países europeos. En 1994 casi no existen diferencias en las tasas de escolarización de niños/as de primaria entre los países europeos del Mediterráneo y los africanos y asiáticos. Es impresionante si se tiene en cuenta que en esos últimos países casi la mitad de la población es analfabeta $^{21}$.

Los países mediterráneos africanos y asiáticos tienen un porcentaje de población infantil elevado, lo que les obliga a utilizar más recursos en servicios para la población joven (como es el caso de la educación) que para la anciana. De los países que las Naciones Unidas consideran que están en vías de desarrollo, los que conforman las orillas sur y este de la cuenca mediterránea (especialmente los que conforman la orilla sur) están entre los que dedican más recursos a la educación de las personas, es decir, a la formación de capital humano. En esos países la escolarización ha pasado de ser un lujo a ser un bien al alcance de casi toda la población infantil. En esos momentos la educación primaria es prácticamente universal. La organización de la enseñanza universitaria en los países del sur y este del Mediterráneo es antigua, pero el sistema educativo en el resto de niveles de enseñanza se desarrolla durante las últimas décadas. La escolarización de prácticamente toda la población infantil es un fenómeno reciente si se compara con los países del norte de la cuenca.

En los países mediterráneos musulmanes, a nivel educativo se está produciendo un avance en la dirección de crear una sociedad culturalmente más igualitaria. Pero los/as analistas del Fondo Monetario Internacional se quejan de que estas inversiones en formación de capital humano no tienen contrapartidas claras en el ámbito económico. Amer Bisat afirma que en los países del norte de África y de oriente próximo «el producto en forma de capital humano obtenido de las inversiones en educación ha sido decepcionante debido a problemas de organización de la enseñanza (que no está vinculada a la práctica laboral), estructuras educativas poco consistentes, e incentivos inadecuados para que las personas que aprenden apliquen esos conocimientos para trabajar» (1996: 18). Sin embargo, a partir del análisis de los datos de calidad de vida a lo largo del tiempo se observa que las inversiones en educación repercuten en

${ }^{21}$ El nivel de educación de las personas de los países del norte y los del sur y este de la cuenca mediterránea es bastante distinto. En el año 1994 los países africanos y asiáticos de la cuenca tienen diez veces más personas analfabetas que los de la Europa mediterránea. El porcentaje medio de analfabetos/as en los países del norte de la cuenca mediterránea es de un 3 por 100 de la población total. En los países del sur y este de la cuenca esta cifra se eleva a más del 35 por 100 de la población total. En el norte, el analfabetismo es un recuerdo del pasado; solamente algunas personas ancianas son analfabetas. En los países de las orillas sur y este el fenómeno del analfabetismo está más generalizado; afecta también de forma masiva a personas de mediana edad. Sobre todo a las mujeres y a las personas que viven en zonas rurales. 
un desarrollo más social que económico. Una mejora de las variables que muestran calidad de vida puede atribuirse tanto a una redistribución de recursos económicos más equitativa como a un aumento de la cultura de las personas que conlleve una mayor capacidad de absorber y entender los flujos de información que llegan. La alfabetización de la sociedad forma parte del desarrollo invisible de los países africanos y asiáticos del Mediterráneo; es una herramienta importante de redistribución y mejora del bienestar de las personas.

\section{PAUTAS SOCIOLÓGICAS DE DESARROLLO}

A partir de la independencia, las élites gubernamentales de los países musulmanes de la cuenca mediterránea adoptan ideologías nacionalistas que se reflejan, por un lado, en una estructura social y económico-industrial de tipo socialista y, por otro lado, en una asimilación de pautas de vida occidentales. Esos procesos llevan a una mejora de las variables indicativas de calidad de vida, implicando un desarrollo social que es más importante de lo que los/as analistas internacionales suponen en sus estudios ${ }^{22}$. La mayoría de análisis de los países musulmanes de la cuenca se centran en la dinámica económica y política $^{23}$. Los estudios reflejan el estancamiento económico de mediados de la década de los ochenta, la aparición de movimientos absolutistas o que la democracia no está plenamente garantizada. El análisis centrado tan sólo en esos factores hace que se pasen por alto aspectos sociales importantes, y que demuestran la existencia de un desarrollo más social que económico o político que se refleja en mejoras de la calidad de vida de las personas.

El desarrollo es invisible para los/as analistas porque la transformación positiva de las variables de bienestar en esos países deriva en parte del rechazo de un modelo único de sistema económico capitalista. Uno de los factores más importantes que explican la mejora de variables indicativas de calidad de vida es el fracaso de la industrialización, que hace que se desarrolle más rápidamente el sector servicios. Argelia y Libia, que son los mayores productores de petróleo en el área del Mediterráneo, son también los países con más problemas económicos durante las dos últimas décadas del siglo XX. Junto con Alba-

${ }^{22}$ Véase el artículo de Mohamed A. El-Erian y Susan Fennell, «Reform and Growth and Overview», publicado en 1996; o también el de Patricia Alonso-Gamo et al., "Adjusting to the New Realities: MENA, the Uruguay Round, and the European Union's Mediterranean Initiative», también de 1996.

${ }^{23}$ Ese punto de vista es manifiesto en las publicaciones que el FMI dedica a los países del norte de África y oriente próximo. Algunos ejemplos son el libro editado en 1997 por Taher Kanaan con el título The Social Impact of Economic Reform on Arab Countries; o los artículos "Growth and Stability in the Middle East and North Africa», de Mohamed A. El-Erian et al. (1996); "The Path to Convertibility and Growth: The Tunician Experience», de Sahle M. Nsouli et al. (1993), o «Economic Dislocation and Recovery in Lebanon», de Sena Eken et al. (1995). 
nia, son los únicos países del área en los que el PIB per capita disminuye durante ese período. La problemática deriva de una dependencia económica del exterior basada en un solo producto. El desarrollo de la economía en esos países ha dependido siempre de la exportación de hidrocarburos. La estrategia principal de desarrollo en Argelia y Libia después de la independencia pasaba por potenciar el sector industrial. La idea era establecer industrias pesadas, estatales, vinculadas al sector energético. La economía se desarrolló alrededor de un sector público importante y controlador. A finales de la década de los ochenta y principios de la de los noventa el desarrollo industrial se vio perjudicado por la recesión económica en los países industrializados de Europa, así como por la Guerra del Golfo. El desarrollo de la economía alrededor de un modelo basado en el control de la industria por parte del Estado fracasó. La economía de los países del sur y este de la cuenca no se desarrolló tanto ni tan rápidamente como en ese momento está previsto que sucediera. Todos los países del área, excepto Libia y Argelia, que eran totalmente dependientes del mercado internacional de hidrocarburos, cambian de estrategia; definen políticas económicas que no son ni capitalistas ni socialistas. Es un modelo mixto en el que los sectores público y privado están claramente delimitados.

Debido al fracaso del proceso de industrialización, el sector secundario es poco importante en las economías de los países mediterráneos más meridionales. El proceso de transformación económica no se produce de la manera habitual, de la agricultura a la industria y de la industria a los servicios. A lo largo de los tres últimos quinquenios, los países del sur y este de la cuenca traspasan trabajadores/as del sector primario directamente al terciario, no al secundario. El sector de servicios se desarrolla a la misma velocidad en los países del sur que en los del norte. Esto representa una evolución más significativa a nivel social que a nivel económico. Mejora la calidad de vida de las personas, lo que se manifiesta en el aumento del consumo de alimentos. Uno de los sectores de la industria que evoluciona positivamente en los países mediterráneos africanos y asiáticos a lo largo de los últimos tres lustros es el de alimentos. Turquía y Egipto producen más del doble de alimentos y bebida en 1993 que en 1980, y el resto de países asiáticos y africanos de la cuenca aumentan la producción en un 50 por 100. La demanda interna de comida en los países asiáticos y africanos crece; se consume más y mejor.

El otro factor importante para explicar el desarrollo de los países del sur y este de la cuenca es la creación de Estados de Bienestar que, aunque fragmentarios, son eficientes en varios de sus servicios. El desarrollo de unos sectores educativo y sanitario con vocación de universalidad deriva de una ideología nacionalista que rechaza el modelo de capitalismo extranjero, al que se culpa del subdesarrollo histórico de los países musulmanes mediterráneos. Los países africanos y asiáticos de la cuenca tienen una proporción de población infantil elevada, lo que les obliga a aplicar más recursos en servicios para la población joven, como es el caso de la educación. De los países que las Naciones Unidas consideran que están en vías de desarrollo, los que conforman las orillas sur y 
este de la cuenca mediterránea están entre los que dedican más recursos a la educación de las personas. En los países mediterráneos africanos y asiáticos la escolarización pasa de ser un lujo a un recurso al alcance de casi toda la población infantil. Actualmente la educación primaria es prácticamente universal. La proporción del PIB que los países del bloque sur del Mediterráneo destinan a financiar el sector de la educación es mayor que la que destinan los del norte. Se crea una generación de jóvenes con educación alta que contrasta con el analfabetismo de la generación de sus padres.

El desarrollo cultural de las personas conlleva una mejora en las posibilidades de la población de absorber y entender los flujos de información que les llegan. La creación de una sociedad civil culta e informada forma parte del desarrollo invisible de los países mediterráneos africanos y asiáticos; es una herramienta potente de redistribución y mejora del bienestar de las personas. Además, es duradera. La economía es volátil, pero las estructuras y cultura de bienestar no tanto. El caso del Líbano es significativo si se analiza con el resto de países del área mediterránea. En el Líbano, a pesar de su PIB per capita bajo en la década de los ochenta y en la de los noventa, las cifras de la mayoría de variables indicativas de calidad de vida son mejores que en el resto de países del sur y este de la cuenca con PIB más elevado y que además experimentan un período de crecimiento económico. Las estructuras y costumbres de bienestar que se crearon entre los/as libaneses durante su período de desarrollo social perduran a lo largo del tiempo, aunque posteriormente existan problemas sociales que conlleven rescisiones económicas importantes. Los datos de las variables indicativas de calidad de vida más básicas en el Líbano, como son las disponibilidades alimentarias o energéticas, mejoran de manera clara a lo largo de la década de los ochenta, sin que a su vez lo hagan las variables económicas.

Los países africanos y asiáticos del Mediterráneo destinan recursos elevados a educación, es decir, a "formación de capital humano», en terminología economicista. También invierten de manera considerable en el sector sanitario. Esas inversiones en sectores sociales no repercuten automáticamente en un desarrollo económico, pero sí en un progreso social y en una mejora de la calidad de vida. Cuando un país crea estructuras de apoyo a la población y se mejora su nivel de bienestar, esas organizaciones de apoyo social perduran a lo largo del tiempo. En el caso de que degeneren, la pérdida de la repercusión positiva que significan en la calidad de vida de las personas es lenta. Las organizaciones y entidades económicas son más volátiles que las sociales; en períodos de crisis degeneran y desaparecen más rápidamente. Ésta es una de las explicaciones del desarrollo invisible de los países del sur y este de la cuenca del Mediterráneo. A diferencia de lo que opinan algunos/as macroeconomistas defensores del libre mercado como Amer Bisat, Mohamed A. El-Erian o Francesco Mongelli, el desarrollo y mejora del bienestar de las personas en un país no debe venir de forma necesaria precedido por una mejora en las variables macroeconómicas de ese país. A veces, como en los países meridionales y orientales de la cuenca, las mejoras de calidad de vida de la población son 
consecuencia de factores de tipo estructural en un proceso histórico. En el caso de los países meridionales de la cuenca, esas mejoras sociales provienen tanto de la creación de políticas sociales e infraestructuras de apoyo a la población como del estancamiento del sector industrial, que provoca una redefinición de la estructura por sectores del sistema económico que conlleva una terciarización rápida de la economía.

\section{BIBLIOGRAFÍA}

Adamson, Kay (1997): Algeria: A Study in Competing Ideologies (Londres: Cassell), 224 pp.

AgHA, Hussain, y KHAlidi, Ahmad (1995): Syria and Iran: Rivalry and Cooperation (Londres: Pinter Publishers), 128 pp.

ANSARY, Abdou Filali (1995): «Perspectivas de las relaciones mediterráneas y el diálogo entre las culturas», pp. 273-284, en Enrique Viaña Remis y Miguel Hernando de Larramendi (eds.), Cooperación cultural en el occidente mediterráneo (Bilbao: Fundación BBV Documenta), 545 pp.

ARNOLD, Guy (1997): The Maverick State: Gaddafi and the New World Order (Londres: Cassell), 192 pp.

AsHIABOR, Alex (1987): «International commodity policy in the UN system: Two decades of experience», pp. 171-178, en Toivo Miljan (ed.), The Political Economy of Nort-South Relations (Petersbourgh: Broadview Press), $704 \mathrm{pp}$.

Axulne, Andrew (1994): The Political Economy of Regional Cooperation: Comparative Case Studies (Londres: Pinter Publishers), 256 pp.

BENDIX, Reinhard (1963): "Concepts and generalizations in comparative sociological studies", American Sociological Review, 28, pp. 532-539.

BERRADA, Abdallah (1994): «Migration, structural change and economic development in Morocco», pp. 267-274, en OECD, Migration and Development (París: OECD), 334 pp.

BISAT, Amer, et al. (1996): "Investment and growth», pp. 7-21, en International Monetary Fund, Building on Progress: Reform and Growth in the Middle East and North Africa (Washington, DC: International Monetary Fund), 69 pp.

BonNell, Victoria E. (1980): «The uses of theory, concepts and comparison in historical sociology», Comparative Studies in Society and History, vol. 22, n. ${ }^{\circ} 2$, pp. 156-173.

BRAUdEL, Fernand (1997): En torno al Mediterráneo (Barcelona: Paidós), 528 pp.

BURKI, Shahid Javed, y AYres, Robert L. (1987): «A fresh look at development aid», pp. 240250, en Toivo Miljan (ed.), The Political Economy of Nort-South Relations (Petersbourgh: Broadview Press), 704 pp.

Cable, Vincent, y Bressand, Albert (1998): Globalization: Rules and Standards for the World Economy (Nueva York: Pinter Publishers), 160 pp.

CAIIs, Jordi (1997): Metodología del Análisis comparativo (Madrid: CIS), 201 pp.

Caïs, Jordi, y CaStilla, Emilio J. (1995): «El sector sanitario», Documentación Social, 101, pp. 228-272.

Caîs, Jordi; Castilla, Emilio J., y Miguel, Jesús M. de (1993): «Desigualdad y morbilidad», pp. 65-112, en Primer Simposio Sobre Igualdad y Distribución de la Renta, vol. VIII: «El impacto de las políticas sociales: Educación, salud, y vivienda» (Madrid: Fundación Argentaria), $181 \mathrm{pp}$.

Cammack, Paul (1997): Capitalism and Democracy in the Third World: The Doctrine for Political Development (Londres: Leicester University Press), 192 pp.

CoHen, Saul B. (1995): «El Mediterráneo occidental en el mundo de la posguerra fría», pp. 2556, en Enrique Viaña Remis y Miguel Hernando de Larramendi (eds.), Cooperación cultural en el occidente mediterráneo (Bilbao: Fundación BBV Documenta), 545 pp. 
Colmoun, Craig (1997): «Nationalism and the public sphere», pp. 75-102, en Jeff Weintraub y Krishan Keemar (eds.), Public and Private in Thought and Practice (Chicago: University of Chicago Press), 380 pp.

Commission of the European Communities (1994): The Demographic Situation of the European Union (Luxemburg: Office for Official Publications of the European Communities), 83 pp.

CruZ, Miguel (1995): «Derechos humanos y religión en el mundo árabe-islámico», pp. 67-82, en Enrique Viaña Remis y Miguel Hernando de Larramendi (eds.), Cooperación cultural en el occidente mediterráneo (Bilbao: Fundación BBV Documenta), 545 pp.

Choueiri, Youssef (1997): Islamic Fundamentalism (Londres: Pinter Publishers), 192 pp.

Darby, Phillip (ed.) (1997): At the Edge of International Relations: Postcolonialism, Gender and Dependency (Londres: Pinter Publishers), 224 pp.

Díez Nicolás, Juan, e IngleHARD, Ronald (eds.) (1994): Tendencias mundiales del cambio en los valores sociales y politicos (Madrid: Fundesco), $770 \mathrm{pp}$.

Dogan, Mattei, y Pelassy, Dominique (1990): How to Compare Nations: Strategies in Comparative Politics (Chatham, NJ: Chatham House Publishers), 211 pp.

EKEN, Sena, et al. (1995): Economic Dislocation and Recovery in Lebanon (Washington, DC: International Monetary Fund), $34 \mathrm{pp}$.

Eken, Sena; Helbling, Thomas, y Mazarei, Adnan (1996): «Fiscal structure and reforms», pp. 23-35, en International Monetary Fund, Building on Progress: Reform and Growth in the Middle East and North Africa (Washington, DC: International Monetary Fund), 69 pp.

El-Erian, Mohamed A., y Fennell, Susan (1996): "Reform and growth: An overview», pp. 1-6, en International Monetary Fund, Building on Progress: Reform and Growth in the Middle East and North Africa (Washington, DC: International Monetary Fund), 69 pp.

El-Erian, Mohamed A., et al. (1996): Growth and Stability in the Middle East and North Africa (Washington, DC: International Monetary Fund), 23 pp.

El-Naggar, Said (ed.) (1994): Financial Policies and Capital Markets in Arab Countries (Washington, DC: International Monetary Fund), 134 pp.

Entelis, J. P. (1989): Culture and Counterculture in Moroccan Politics (Boulder: Westview Press).

EsteVA, Jordi (1998): Mil i una voces (Madrid: Aguilar), 313 pp.

Hantrais, Linda, y Mangen, Steen (eds.) (1996): Cross-National Research Methods in the Social Sciences (Londres: Pinter), 230 pp.

Hitchner, Dell G., y Levine, Carol (1967): Comparative Government and Politics (Nueva York: Dodd, Mead).

ILO, International Labour Organization (1992): World Labour Report 5: Human Rights at Work: Employment, Labour Relations, Social Protection and Working Conditions, Statistical Appendix (Ginebra: ILO).

INTERNATIONAL MONETARY FUnd (1987): "The role of foreign direct investment in development», pp. 213-219, en Toivo Miljan (ed.), The Political Economy of Nort-South Relations (Petersbourgh: Broadview Press), 704 pp.

- (1996): Building on Progress: Reform and Growth in the Middle East and North Africa (Washington, DC: International Monetary Fund), 69 pp.

KanaAn, Taher (ed.) (1997): The Social Impact of Economic Reform on Arab Countries (Washington, DC: International Monetary Fund), $129 \mathrm{pp}$.

KASMI, Mohamed Tayeb (1994): "The construction industry in Algeria and new forms of international co-operation", pp. 187-192, en OECD, Migration and Development (París: OECD), 334 pp.

KHADER, Bichara (1992): L'Europe et le grand Maghreb (París: Louvain-la-Neuve), 364 pp.

KoHN, Melvin L. (1989): "Cross-national research as an analytic strategy», pp. 77-102, en Melvin L. Kohn (ed.), Cross-National Research in Sociology (Newbury Park, California: Sage Publications), $424 \mathrm{pp}$.

Lacomba, Joan (1997): Sociedad y politica en el Magreb (Madrid-Valencia: Universidad de Valencia), $172 \mathrm{pp}$. 
LAPIDUS, Ira M. (1988): A History of Islamic Societies (Cambridge: Cambridge University Press), $1.002 \mathrm{pp}$.

MANyer, Josep (1996): Quan l'islam truca a la porta: Per a una aproximació cultural als musulmans de Catalunya (Barcelona: Editorial Alta Fulla), 127 pp.

Miguel, Jesús M. de (1976): Health in the Mediterrranean Region: A Comparative Analysis of the Health Systems of Portugal, Spain, Italy, and Yugoslavia (Ann Arbor, Michigan: University Microfilms), tesis doctoral en Yale University, 2 vols.

Miguel, Jesús M. de; Caîs, Jordi; Castilla, Emilio J., y Salcedo, Juan (1993): Demographic Imbalances Between Countries of the Mediterranean Basin (Estrasburgo: CDPO del European Council), 66 pp.

Miguel, Jesús M. de; Castilla, Emilio J., y Caîs, Jordi (1994): La sociedad transversal (Barcelona: Fundació la Caixa), 312 pp.

Mounoud, El Mouhoub (1993): «Enterprise relocation, north-south economic relations and the dynamics of employment", pp. 165-174, en OECD, The Changing Course of International Migration (París: OECD), 264 pp.

Nsouli, Sahle M., et al. (1993): The Path to Convertibility and Growth: The Tunisian Experience (Washington, DC: International Monetary Fund), 25 pp.

- (1995): Resilience and Growth Through Sustained Adjustment: The Moroccan Experience (Washington, DC: International Monetary Fund), 29 pp.

Ragin, Charles (1987): The Comparative Method (Berkeley: University of California Press), 185 pp.

Saunders, Paul, y Klau, Frank (1985): The Role of the Public Sector: Causes and Consequences of the Growth of Government (París: OECD), 239 pp.

SpIKer, Paul (1995): Social Policy: Themes and Approaches (Londres: Prentice Hall), 278 pp.

Tachau, Frank (ed.) (1995): Political Parties of the Middle East and North Africa (Londres: Mansell), 736 pp.

United Nations (1982): Demographic Yearbook 1980 (Nueva York: United Nations), 973 pp.

- (1986): Statistical Yearbook 1983/1984 (Nueva York: United Nations), 1.137 pp.

- (1994): Demographic Yearbook 1992 (Nueva York: United Nations), 823 pp.

- (1995a): Demographic Yearbook 1993 (Nueva York: United Nations), 1.032 pp.

- (1995b): Statistical Yearbook 1993 (Nueva York: United Nations), 841 pp.

- (1996): Demographic Yearbook 1994 (Nueva York: United Nations), 1.131 pp.

WaInes, David (1995): An Introduction to Islam (Cambridge: Cambridge University Press), 332 pp.

WALLERSTEIN, Immanuel (1984): El moderno sistema mundial (Madrid: Siglo XXI), 2 vols., 580 y $524 \mathrm{pp}$.

\section{ABSTRACT}

The development of the Mediterranean basin countries is an important sociological experiment. This article analyses the recent evolution of some factors which help to explain the improvement in quality of life which has occurred over the last two decades of the 20th century in countries to the south and east of the Mediterranean basis. Quality of life is considered to be a factor, linked to culture, the life system, and development, which is measured in terms of wellbeing and not in economic terms. The article analyses the atypical evolution of economic sectors and the labour market in the African and Asiatic countries situated in the basin in comparison to that of the European countries. Also assessed is the creation and putting into operation of public policies by African and Asiatic governments, and their effectiveness is contrasted with the policies applied in the European Mediterranean countries. 